[YTV] ميثاق خير الله جلود

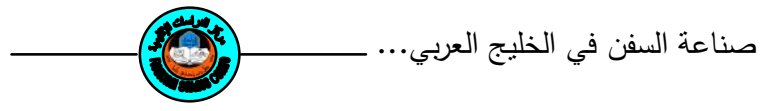

صناعة السفن في الخليج العربي واثر اكتثاف النفط

في تلدهورها

ميثاق خيرالله جلود

مدرس/ قسم الدراسات السياسية والإستراتيجية

مركز الدراسات الإقليمية/ جامعة الموصل الإنئل

مستخلص البحث

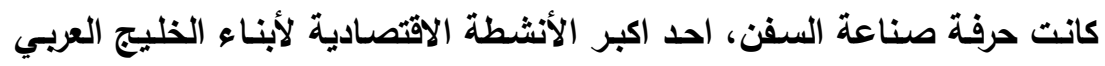

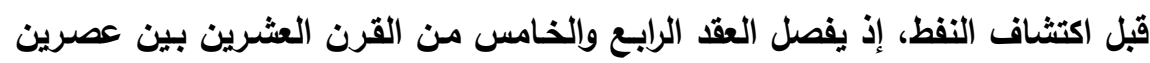

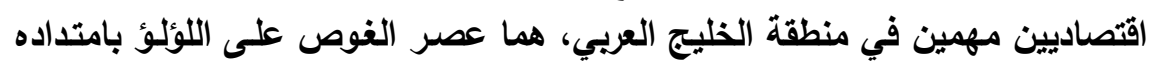

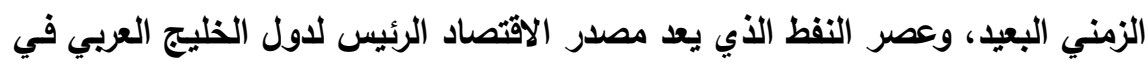

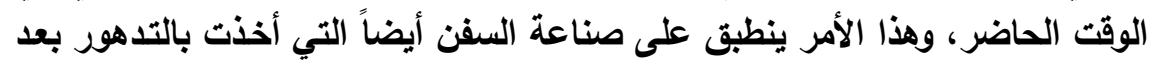

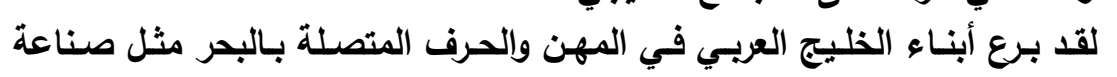

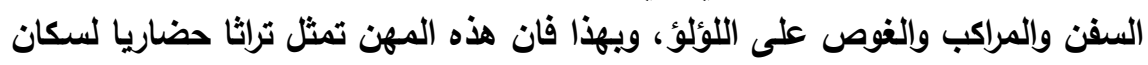

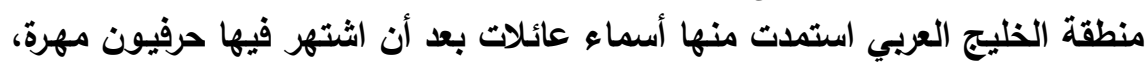

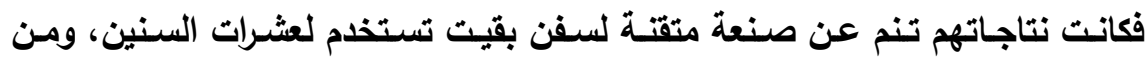
الضروري المحافظة على هذه الحرفة المميزة وتطوريها.

مقدمة - 20 - مقام

كانت اقتصاديات الخليج العربي قبل عصر النفط تعتمد على مجموعة

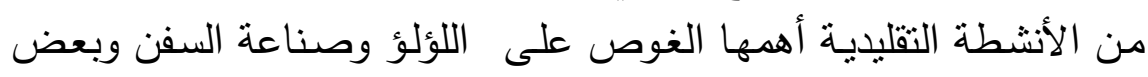

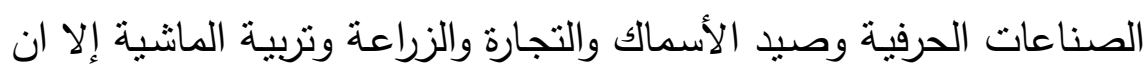

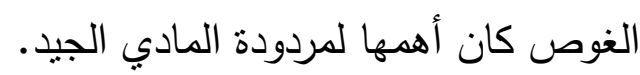
لقد زاول سكان الخليج العربي حرفة صناعة الهندي السفن منذ قرون، واستمروا على ذلك حتى منتصف القرن العشرين، وكان هذا العمل احد اكبر الأنشطة 


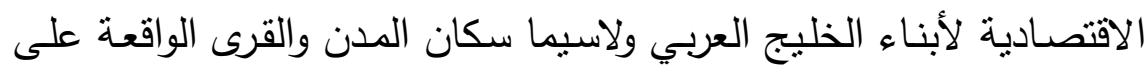
الثـاطئ قبـل اكتشـاف الـفطـ. إذ يفصـل العقد الرابـع والخـامس مـن القـرن العشرين بين عصرين اقتصـاديين مهمين في منطقة الخليج العربي، هما

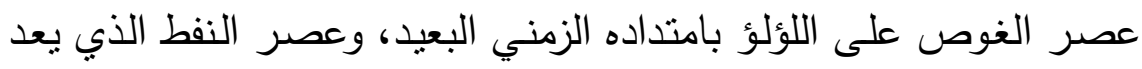

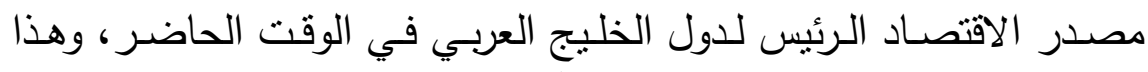

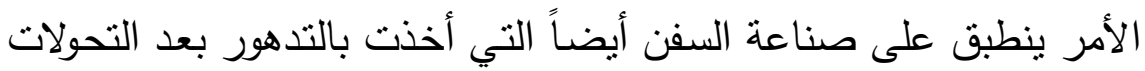
التي طرأت على المجتمع الخليجي. جاءت الثروة النفطية لتغير الحياة في منطقة الخليج العربي لاسيما بعد

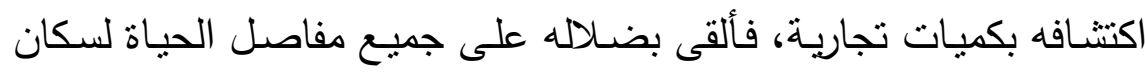
الخليج العربي مـن الجوانـب السياسية والاقتصـادية والاجتماعيـة والتقافيـة. يحاول البحث تسليط الضوء على حرفة صناعة السفن في الخليج العربي وأثزها الاقتصادي والأسباب التي أدت إلى تراجعها واثز النفط في ذلك. وقد اشتمل البحث على محورين: ا - صناعة السفن في الخليج العربي البئ r- اثز اكتشاف النفط في صناعة السفن في الخليج العربي

\section{أولاً: صناعة السفن في الخليج العربي}

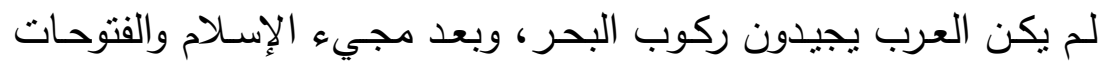

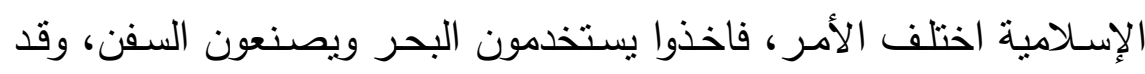

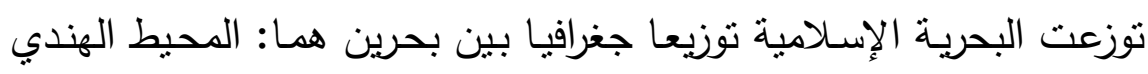

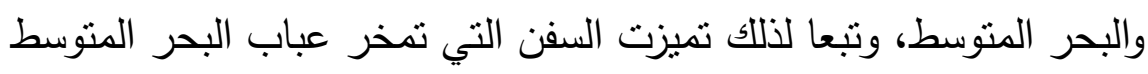

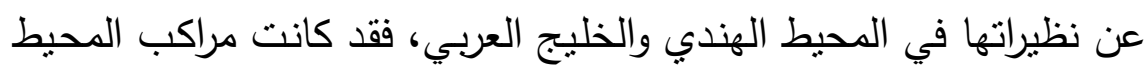

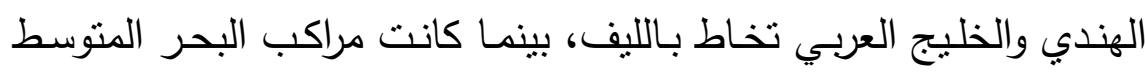

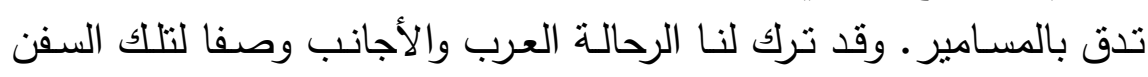
ولعل مراجعة بسيطة لما كتبه (ابن جبير) في القرن الثاني عثر الميلادي، 


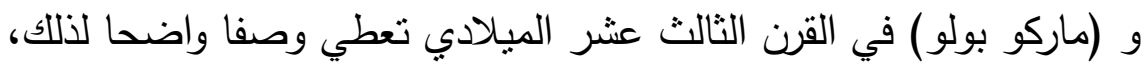

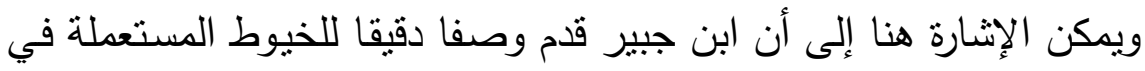

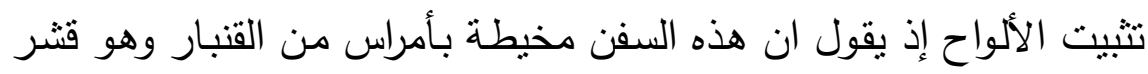

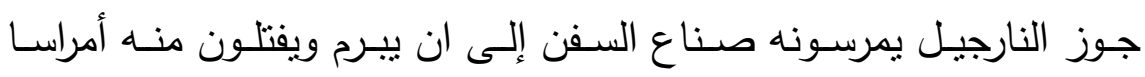

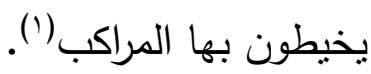

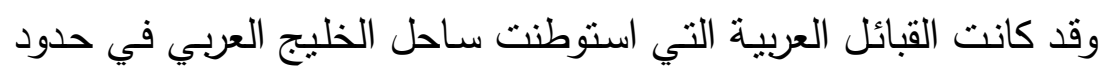
القرن الثالث الميلادي وتعلدت ركوب البحر ، الأكثر قدرة على صناعة السيات السفن

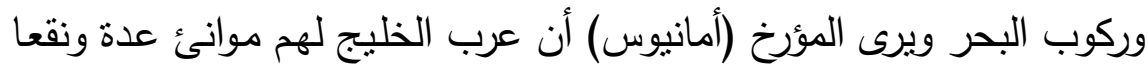

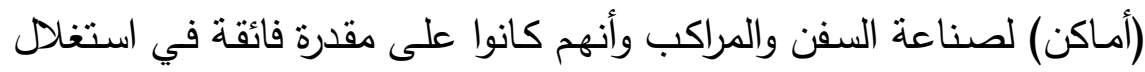

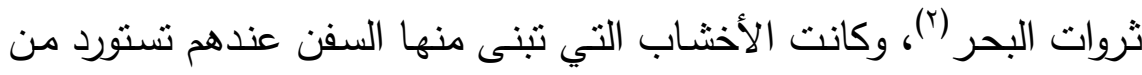

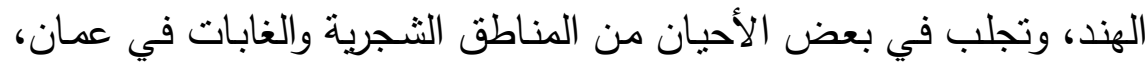

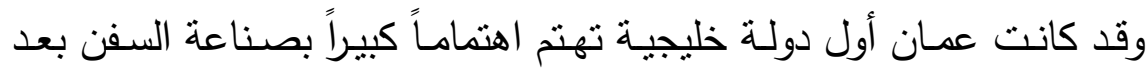

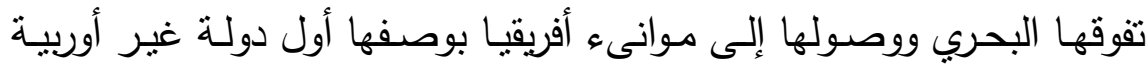

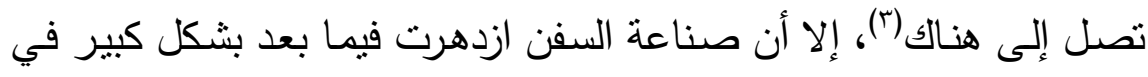

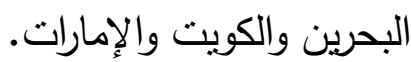
وتقت الطريقة التي صنع بها عرب الخارت الخليج السفن نوثنقاً دقيقاً في المعاجم

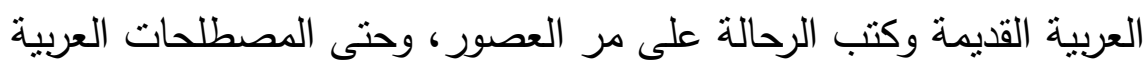

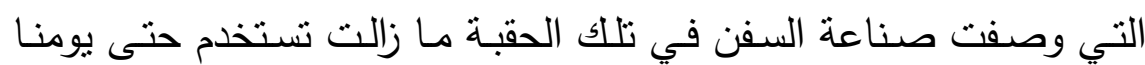

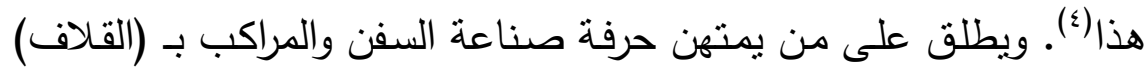

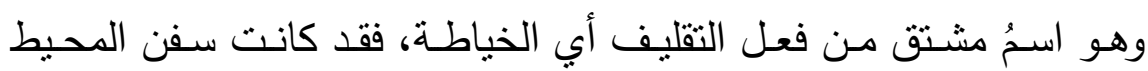

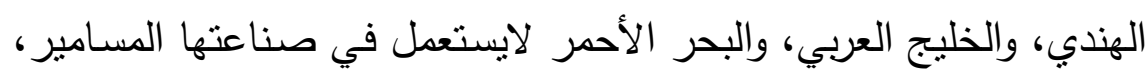

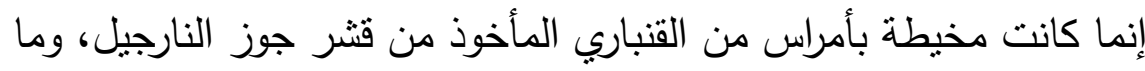

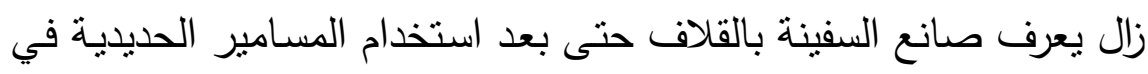

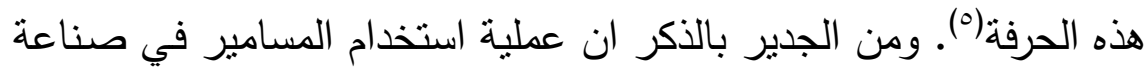

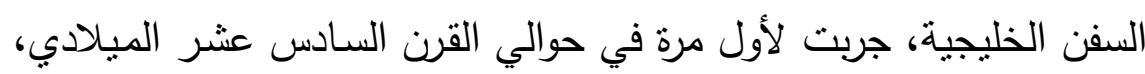


عندما غزا البرتغاليون الخليج العربي، فأكتتف القلافون في هذه المنطقة

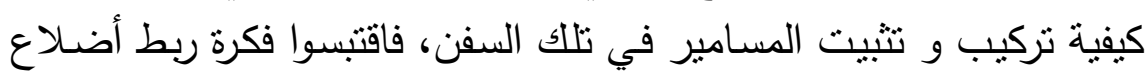

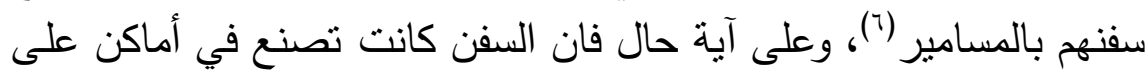

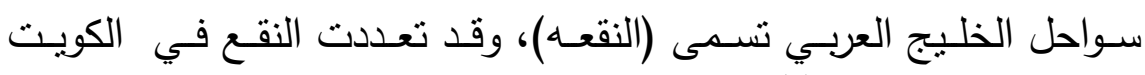
والبحرين والإمارات... (v).

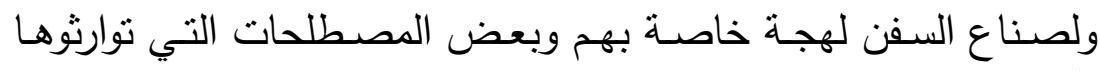
أيضاً، والتي امتزجت بثقافات بعض الثنعوب التي كانت لها ولها علاقة بالتجارة

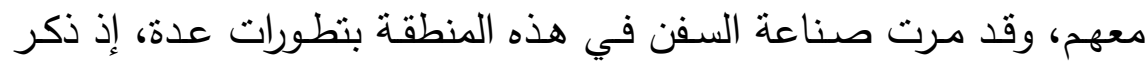

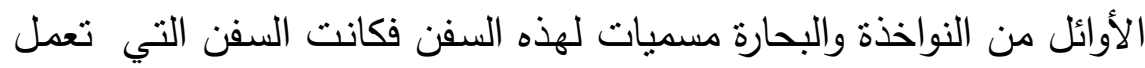

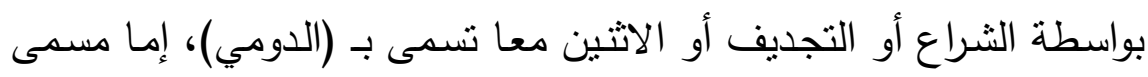

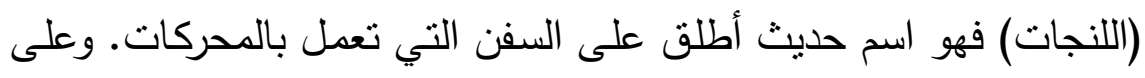

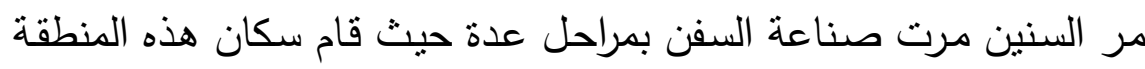

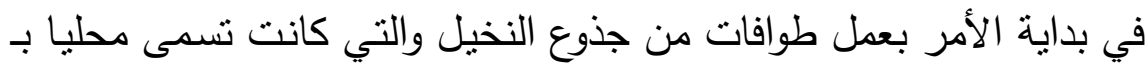

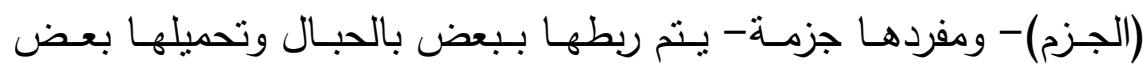

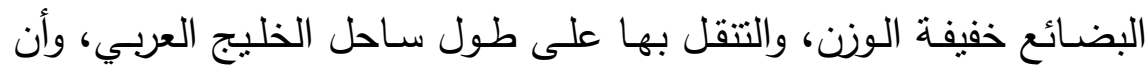

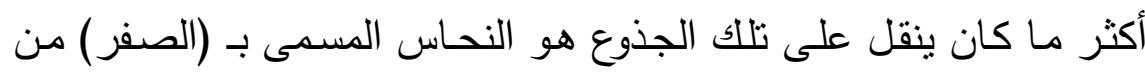

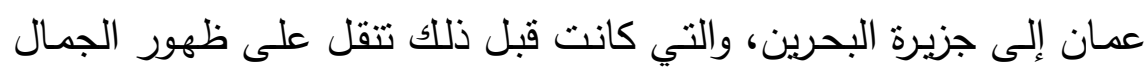

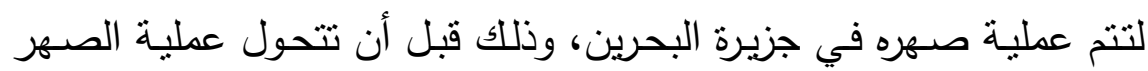

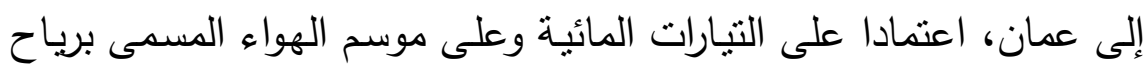

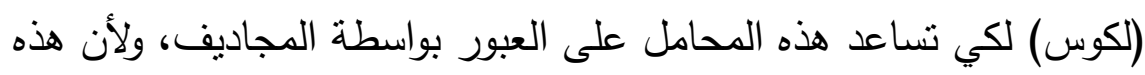

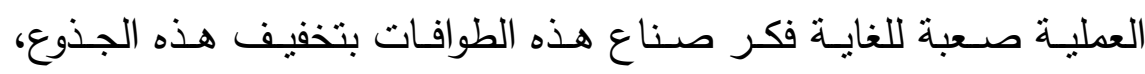

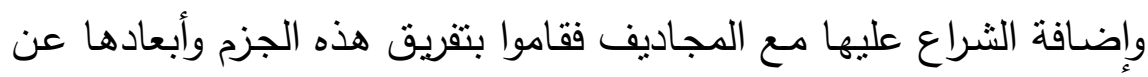

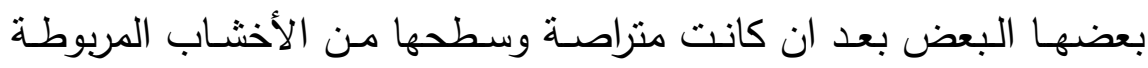

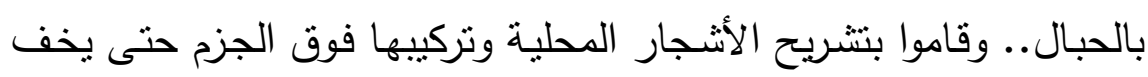


[YVI] [ميثاق خير الله جلود

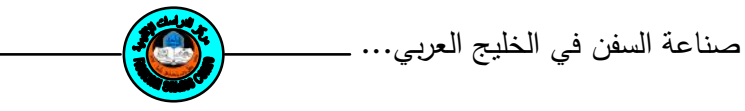

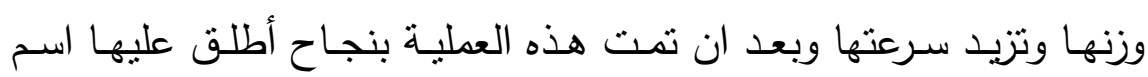

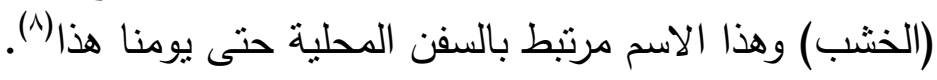

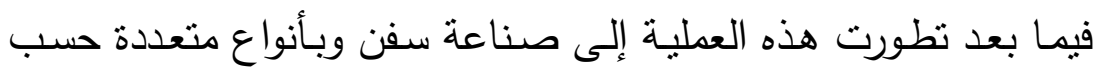

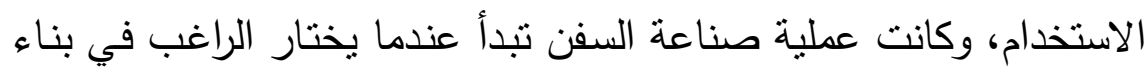

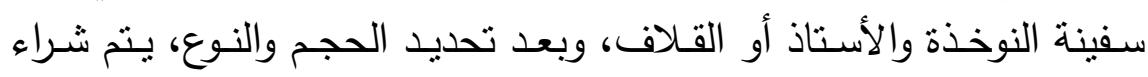

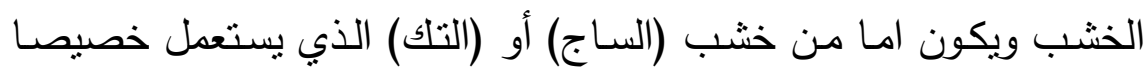

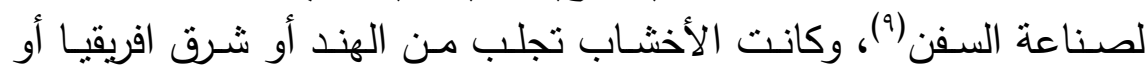

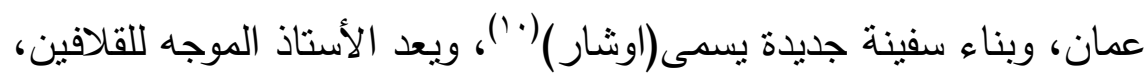

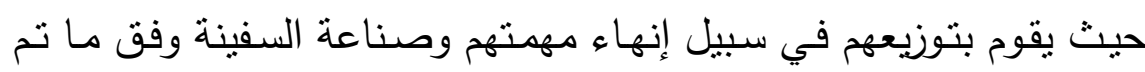

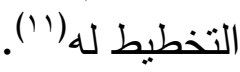

وتبدأ عملية الصناعة بـ (التقليف) وهي عملية ربط ألواح السفينة ببعضها

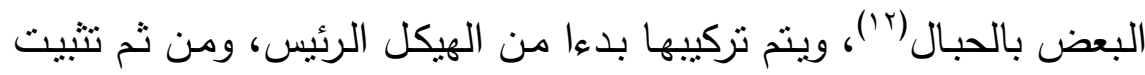

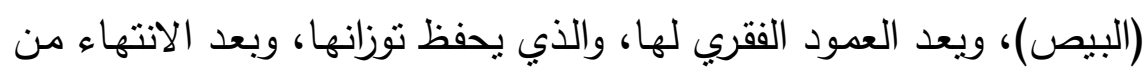

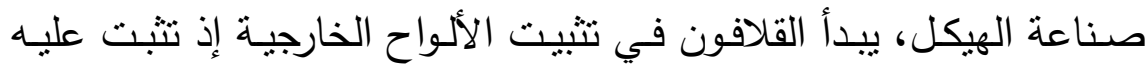

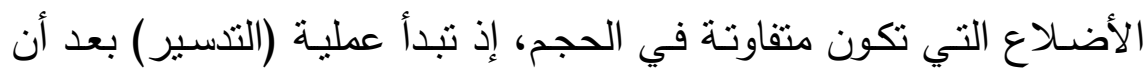

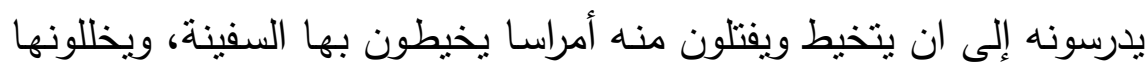

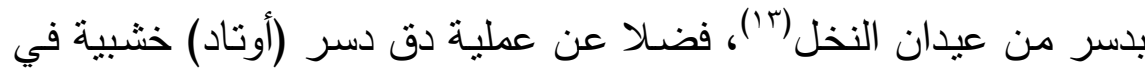

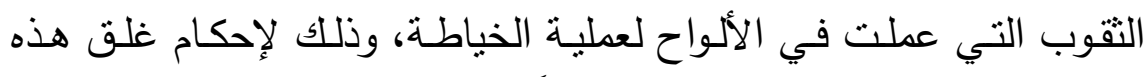

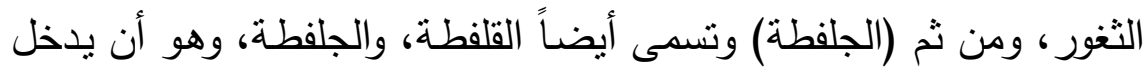

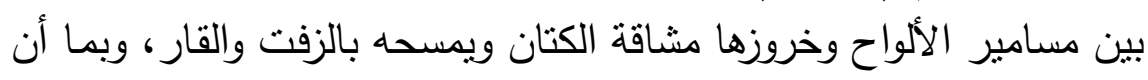

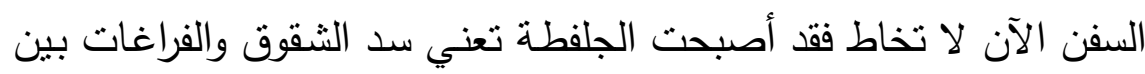

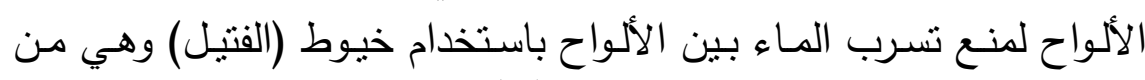

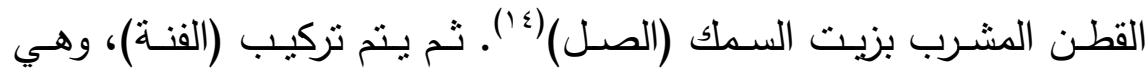

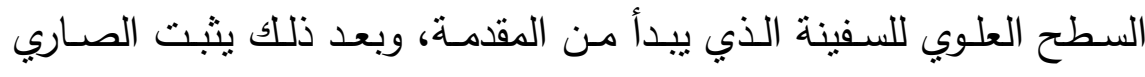
(الدقل) المخصص لحمل الثـراع، ويشـد بالحبال، وبواسطته يقوم الربـان 
بالتحكم بالسفينة، كذلك يتم تثبيت (الكمر) ويوضـع في منتصف الهيكل،

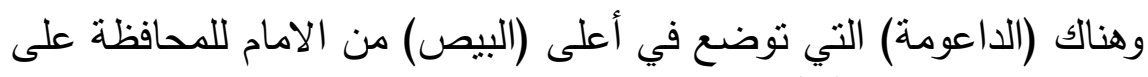
السفينة من الارتطام (10).

بعد اكتمال السفينة بصيغتها النهائية تبدأ مرحلة الدهان الخارجي للسفينة

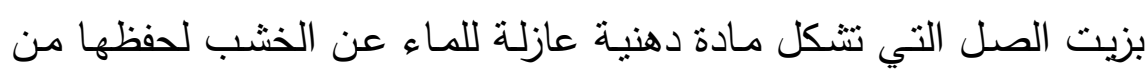
التآكل بسبب الرطوبـة والحشرات. ومن ثم تدهن بالسمن أو بدهن الخروع،

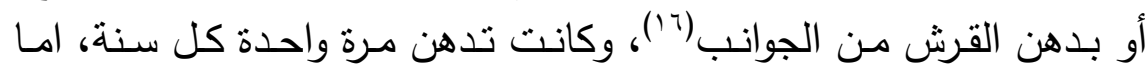
سطح السفينة الخارجي فكان يغلف بخليط من الثحم والطلاء الأبيض بعد

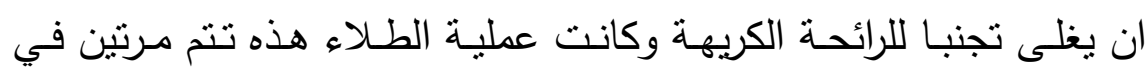

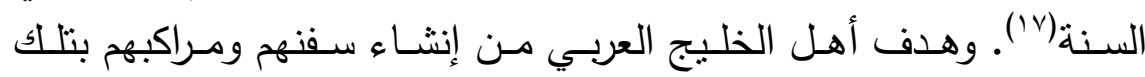

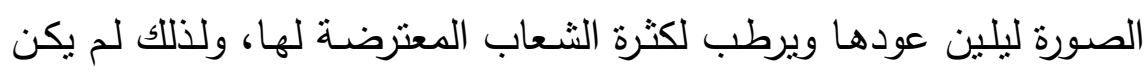
المركب المسماري مرغوبا(1'). ويكون شكل السفينة مقوساً، ويمتد من مقدمتها إلى مؤخرتها، ويكون كل مل فرغال

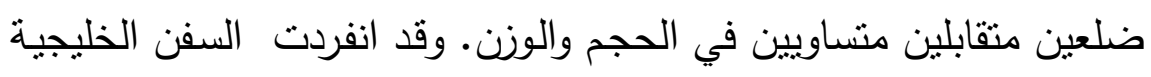

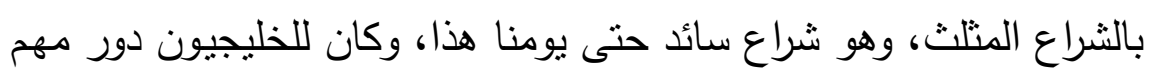
في نقل هذا الشـراع إلى البحر المتوسط، وممـا يؤكده البـاحثون أنـه لـولا

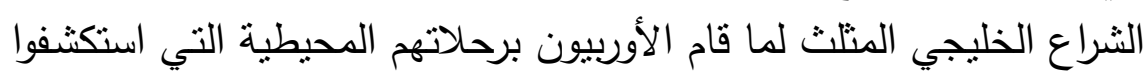

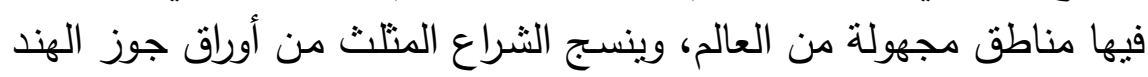

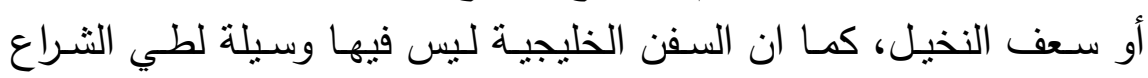

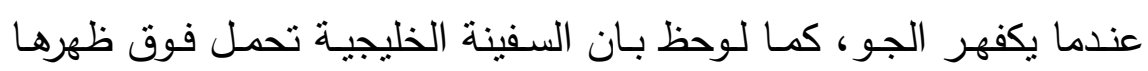

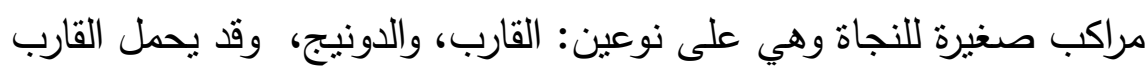

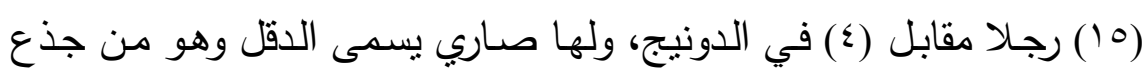
النخيل، وقد يصل طوله إلى (1) (V) قدما، أما الانكر (المرساة) فكان غليظا

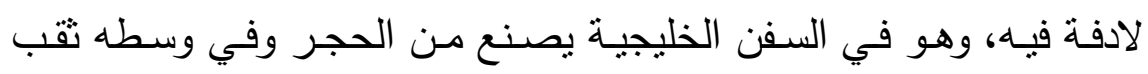

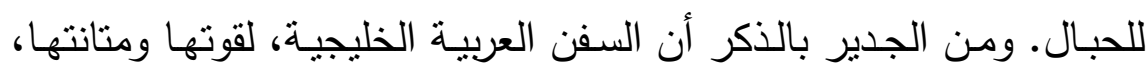


[YVT] [ميثاق خير الله جلود

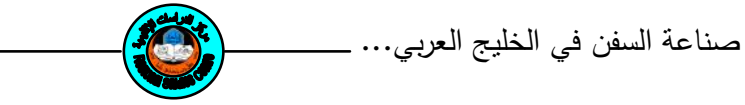

عرفت في الهند باسم (ماداراتا) و تعني (مدرعات)(9) - وبالرغم من الطريقة

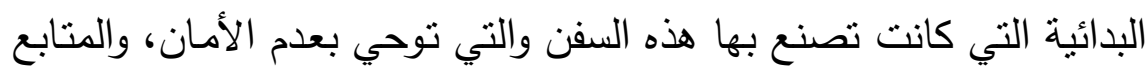

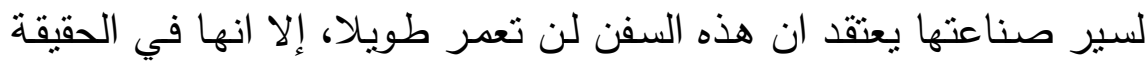

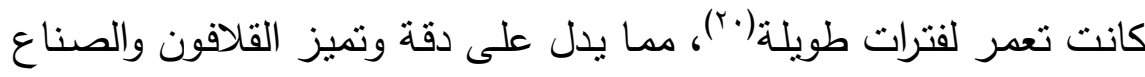

وأخيراً تنزل السفينة إلى البحر حيث تسـب على ألواح خشبية دائريـة المهرة.

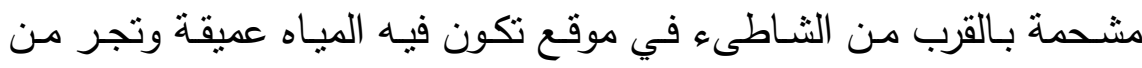

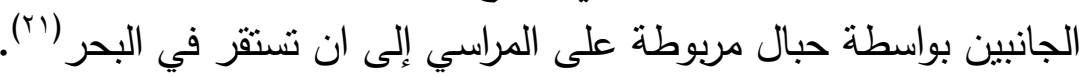

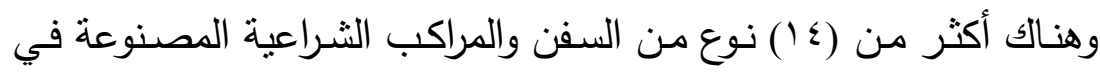

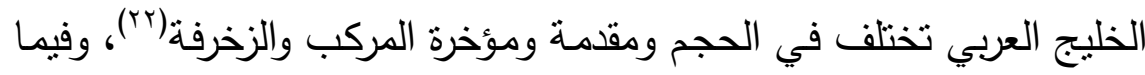
يلي وصف لأهم أنواع السفن في منطقة الخليج العربي:

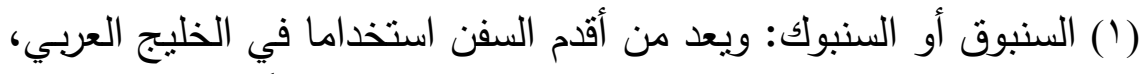

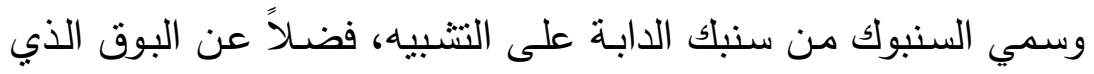

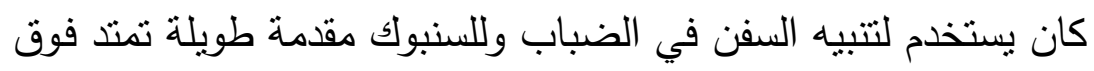

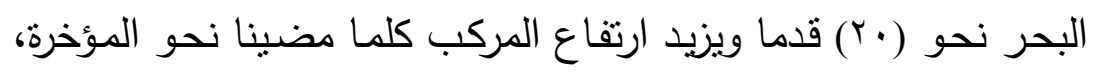

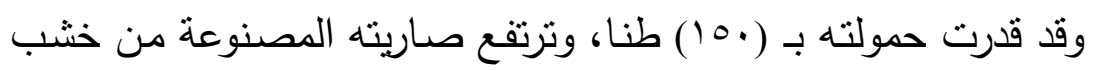

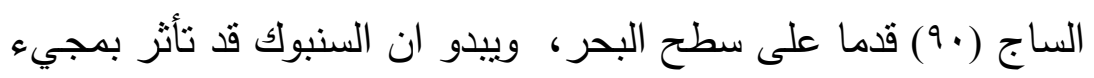

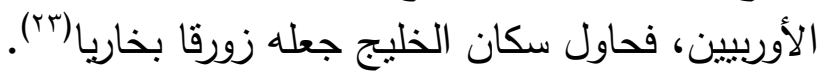

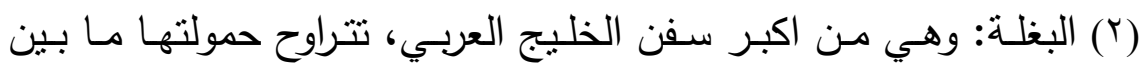

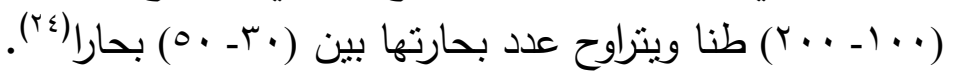

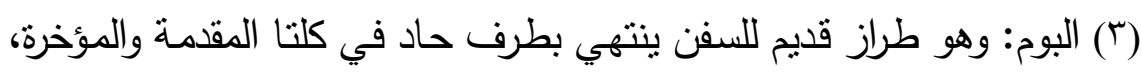

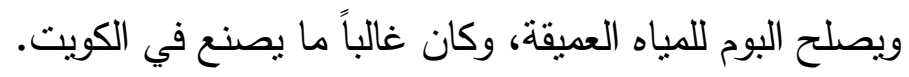

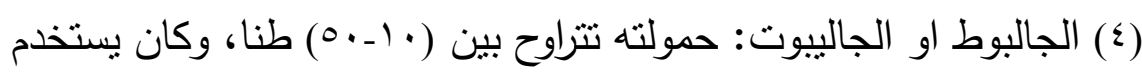
في الخليج العربي ضمن أسطول صيد اللؤلؤ، كذلك يستخدم في ميناء بوشهر بكثرة(ro). 
الغلافة: ظلت هذه السفينة شـائعة الاستعمال على طول السـاحل الغربي

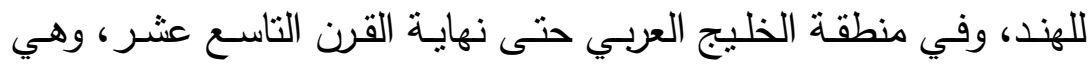

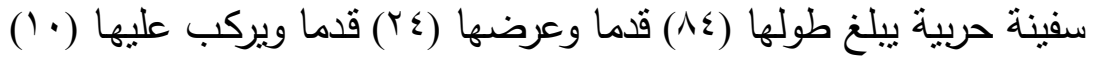

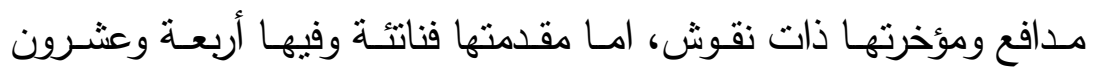

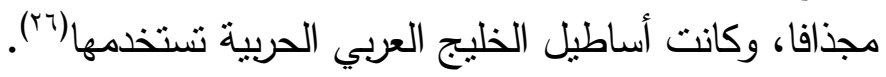

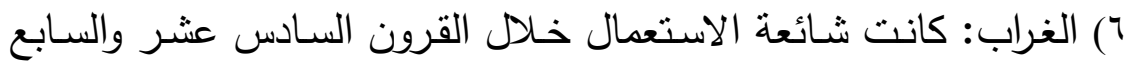
عشـر والثامن عثـر على سـواحل مالابـار، والخليج العربـي، والبحر الأحمر، والعادة أن يكون الغراب سفينة ذات ثلانث صاريات، وقد سميت

$$
\text { بهذا الاسم لان مقدمتها نتبه رأس الغراب. }
$$

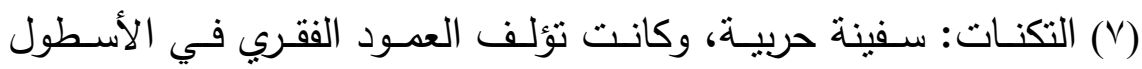

$$
\text { العثماني في البصرة. }
$$

(^) الترانكي: نوع من السفن كان شائع الاستعمال في الخليج العرب، يسير بالمجذاف والثراع معا ويستخدم في الحرب والتجارة(rV(N). ولكنه لم يشاهد

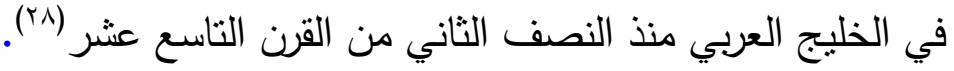

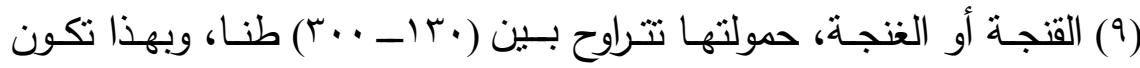

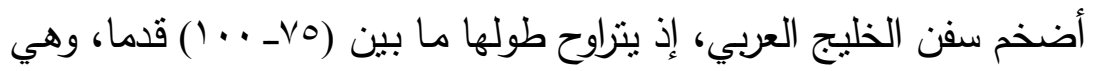

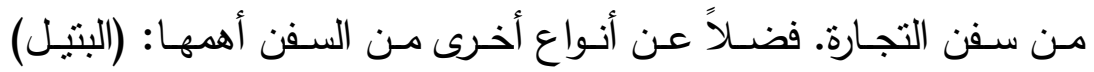
(الثـوعي) ويعرف في العراق بـ (الثـويعي) (البقارة) (الـزاروك) (الدنكيـة)

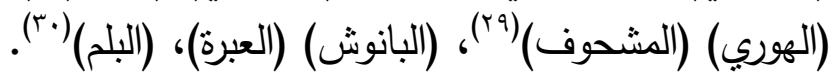

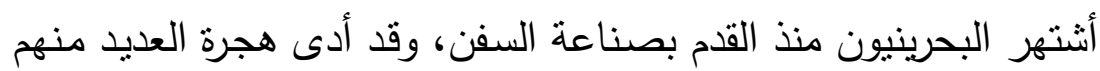

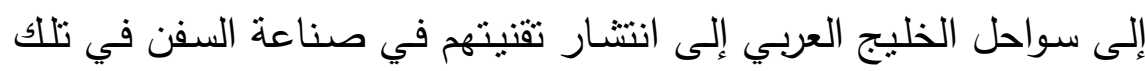

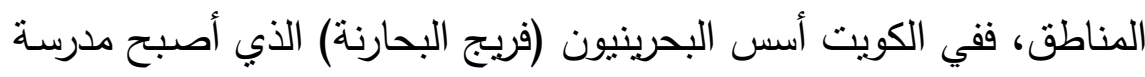

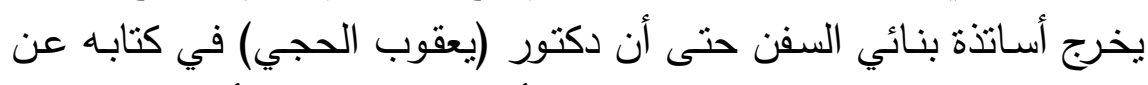

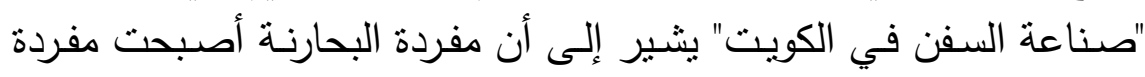

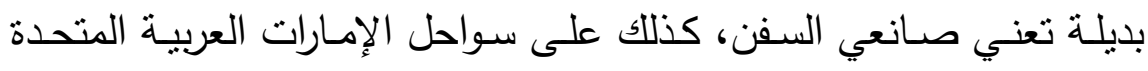


وبالتحديد سواحل دبي تأسس أيضا (فريج البحارنة) وبدأ مع تأسيسه تطور

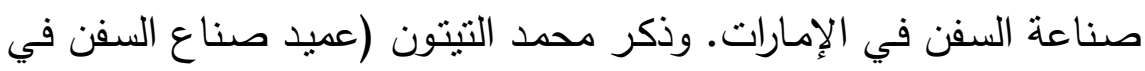

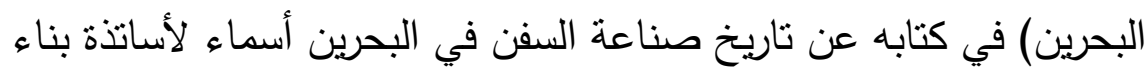

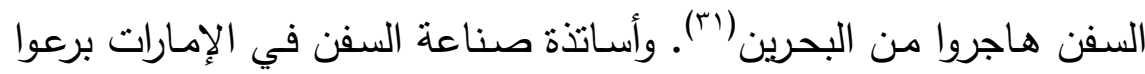

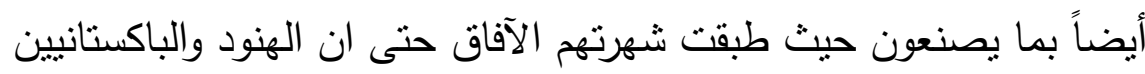

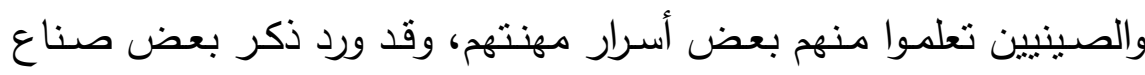

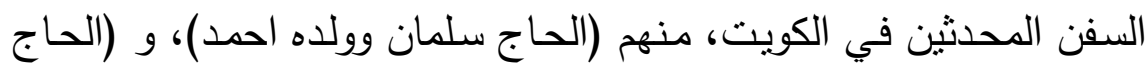

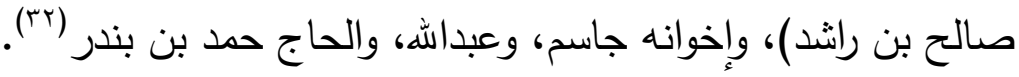

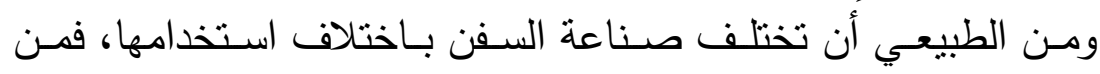

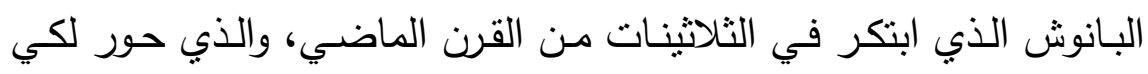

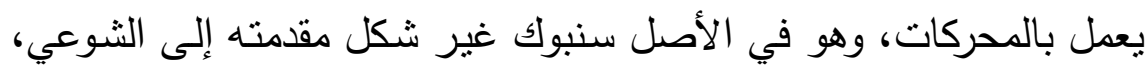

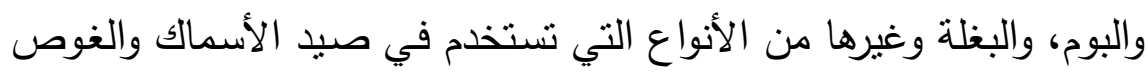

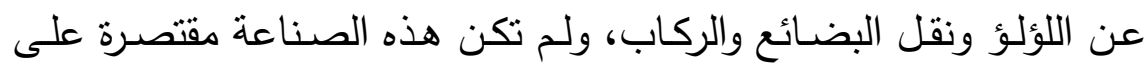

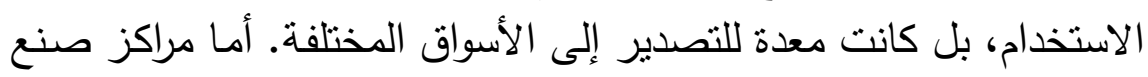

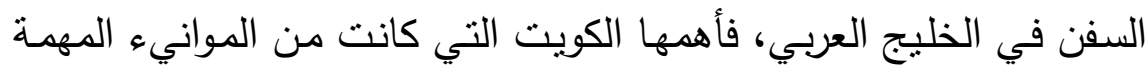

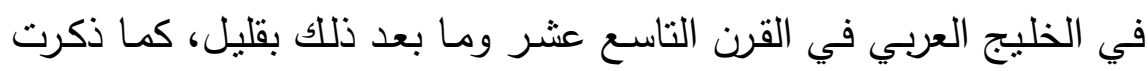

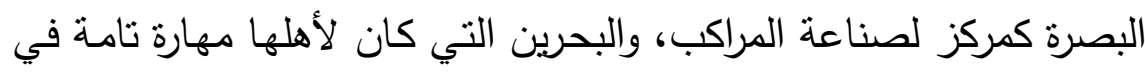

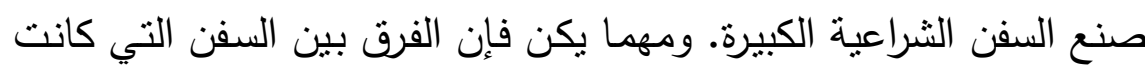

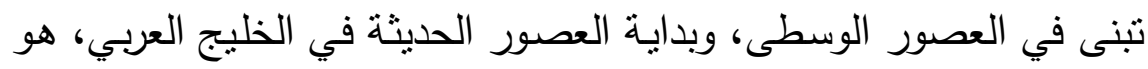

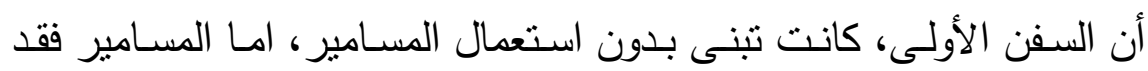

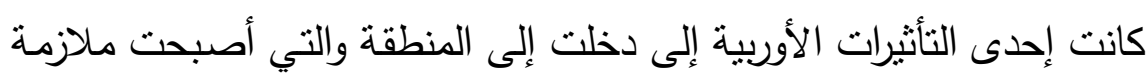
لصناعة السفن الخليجية(rT)

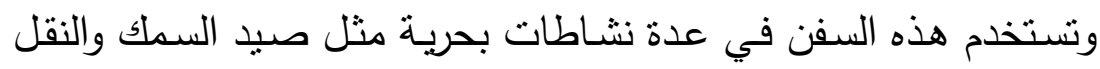
التجاري والغوص في مصائد الؤلؤ ، الذي كان يعد ألهات أهم استخداماتها إذ ينقسم

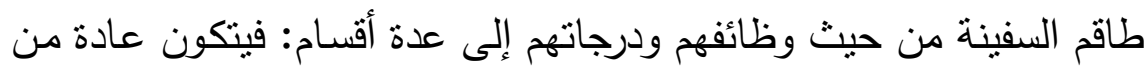




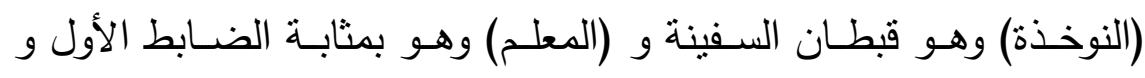

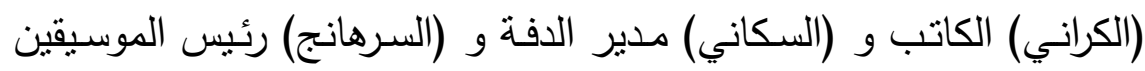

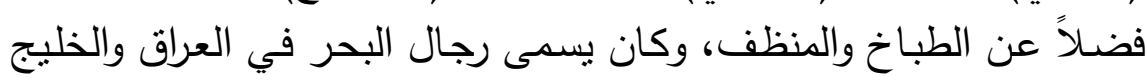

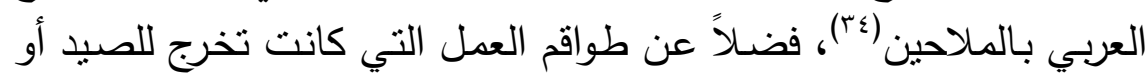

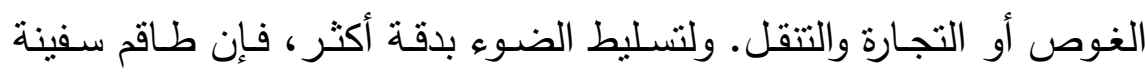

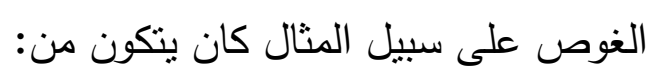

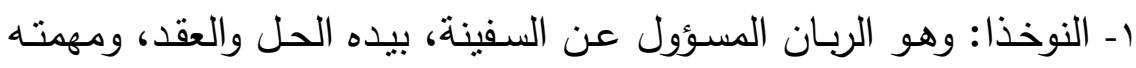

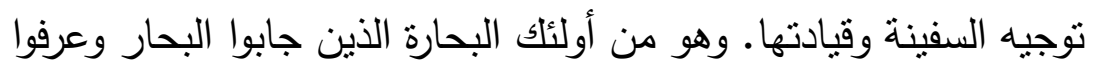

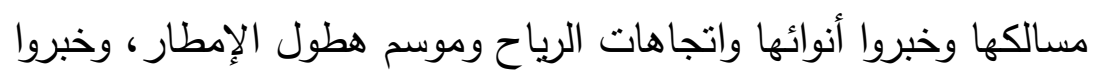

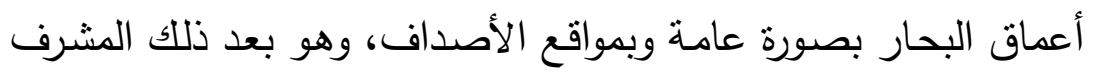
على أدارة السفينة. r- الغواصون: ويتراوح عددهم بين العشرة والأربعين، ويتوقف ذلك بطينة الكيعة

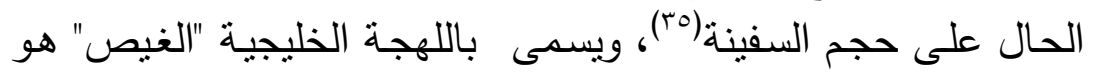

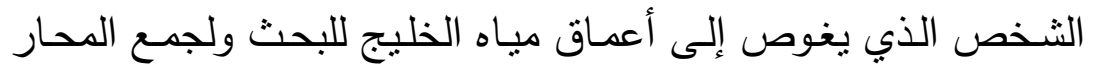

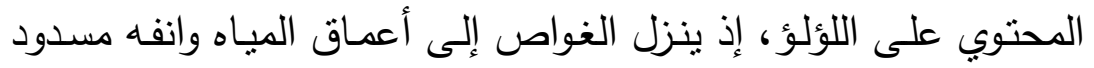

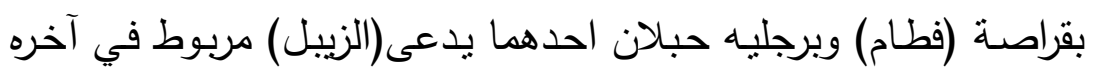

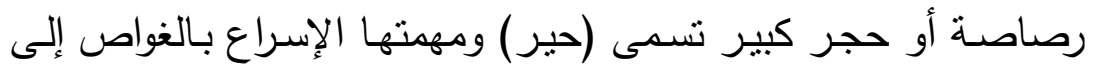

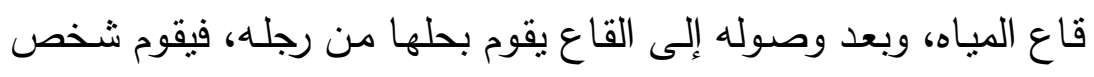

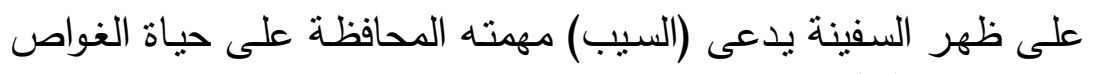
بسحب النقل (بَ). أما الحبل الثاني فيطلق عليه (الجدا) ويمثل حبل النجاة

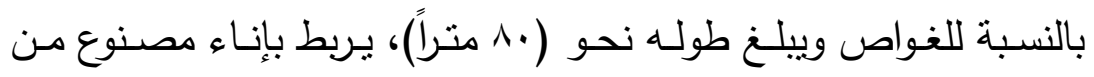

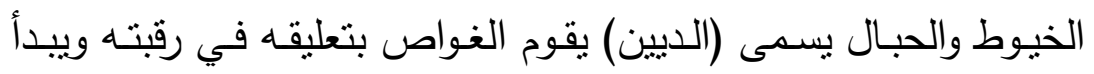

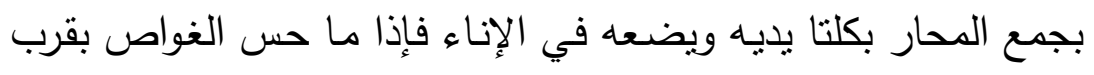

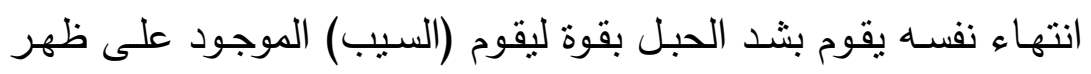


ميثاق خير الشه جلود [ ] [ ]

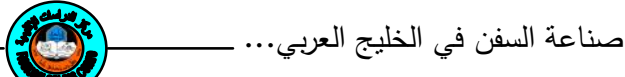

السفينة برفعه من الماء (YV). ويقوم الغواص عادة بتسعين غطسه (تبه)

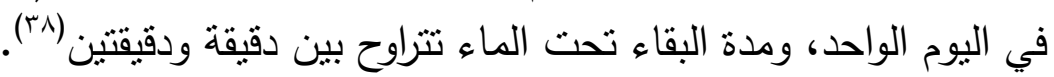

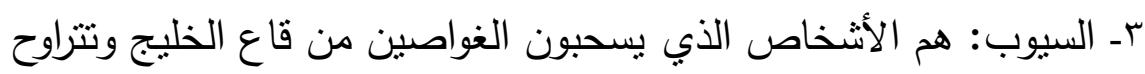
إعدادهم أكثر بقليل من عدد الغواصين على ظهر السفينة عند أول إثنارة

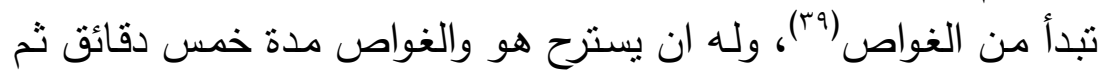
تبدأ فترة جديدة، كما على الغواصل، وله السيب العمل في السفينة في كل ما تنطلبه

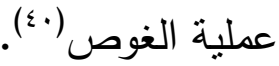

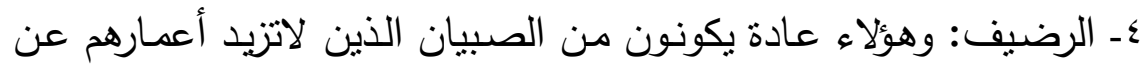

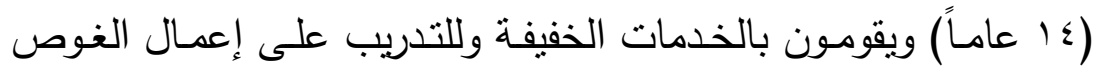
ويقومون أحيانا مقام السيوب. هـ التباب: لا يزيد عددهم في السفينة عن أربعة أو خمسة صبيان ومهنته

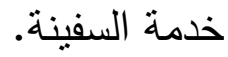
זـ الغزال: يكون في بعض السفن الكبيرة شخص واحد ويغوص على حسابه

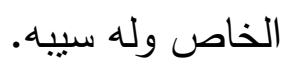

Yـ الجعدي: الثخص الذي يحل محل النوخذا في السفينة.

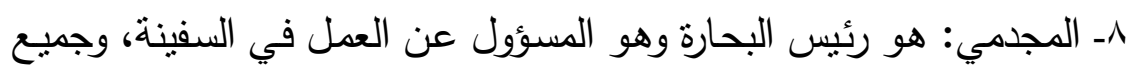
السفن الكيبرة يكون فيها المجدمي، كما يكون في السفن الكيبرة نحو خمسة الكية

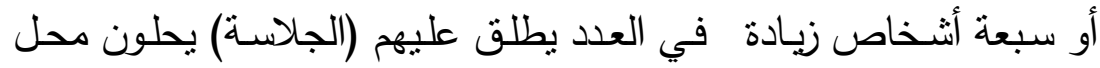

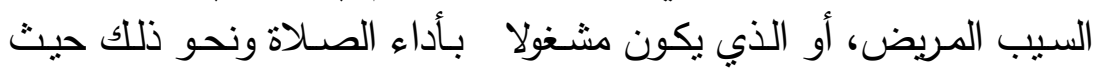

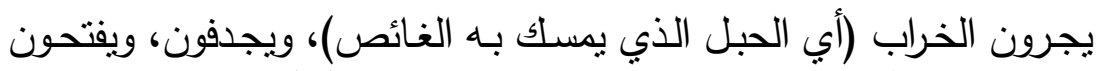

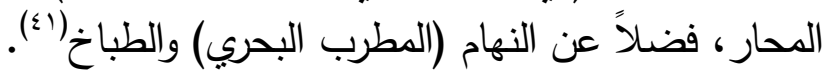

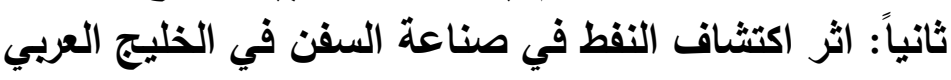

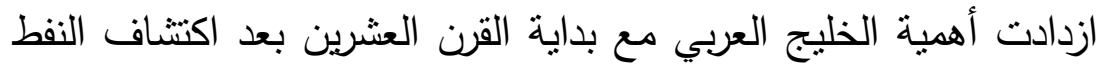

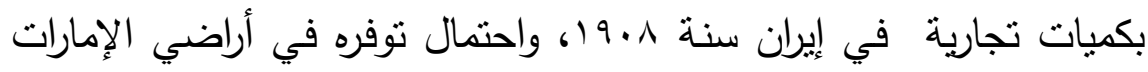

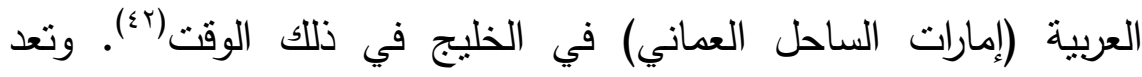

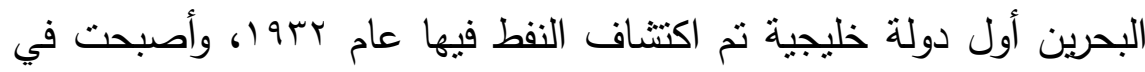


حينها محطة انطلاق لاكتشاف النفط في الدول الخليجية المجاورة، في

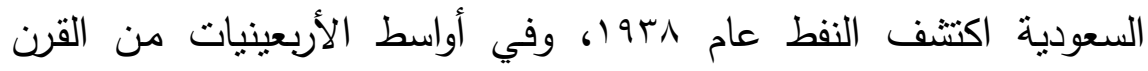
الماضي نم اكتشاف النفط بكميات هائلة بشرق المملكة العربية السعودية وقد سيطرت شركة (ارامكو) الأمريكية على الامتيازات النفطية في المملكة. اما

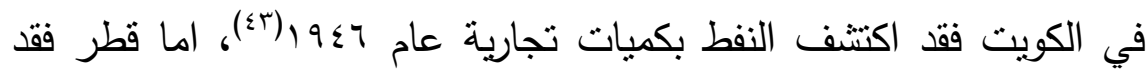
اكتثف النفط فيها عام 9 19 وحملت أول شحنة من ميناء مسيعيد، وأبو

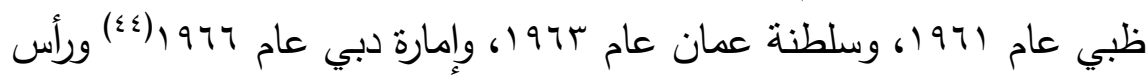
الخيمة عام 9VV I. وقد احدث اكتشاف النفط واستغلاله تغيرات جذرية واضحة في البنية الاقتصادية والطبيعة الإنتاجية والاستهالاكية السائدة قبل عصره، إذ كانت اقتصاديات المنطقة تعتمد على مجموعة من الأنشطة الأنه

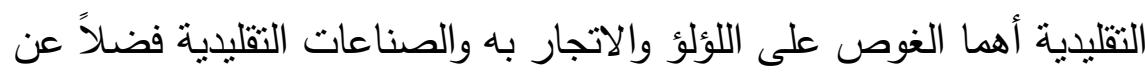

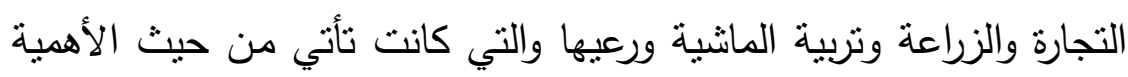

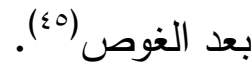

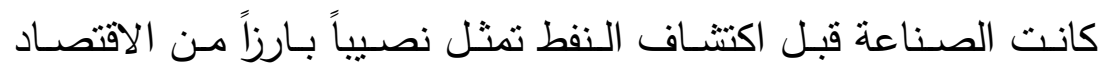

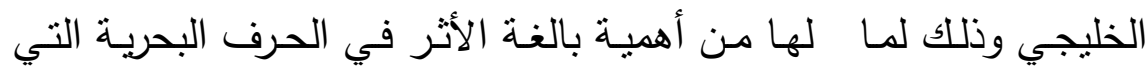
يمتهنها سكان الخليج العربي، ولم تكن الصناعة تعتمد على شهادات دراسية باتية

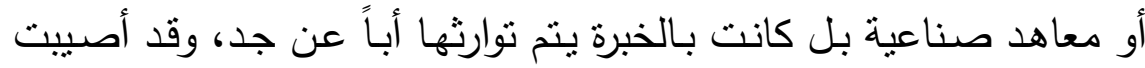

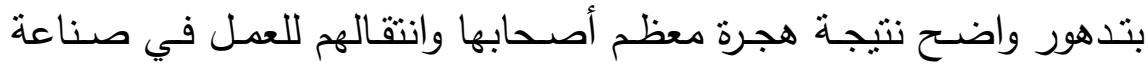

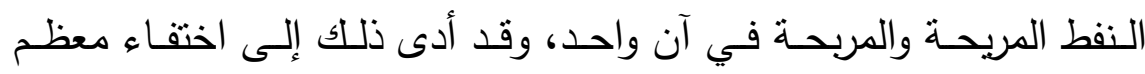

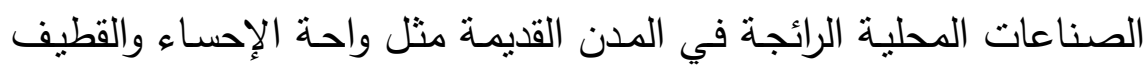
في السعودية وينطبق ذلك على بلدان الخليج الأخرى فقد كانت المنطقة قبل الته

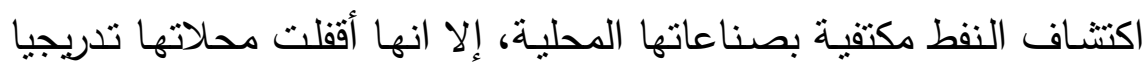
نتيجة التحاق كثير من الصناع بوظائف صناعة النفط، مما سبب تدهوراً سربعاً للصناعات التقليدية المحلية، وهكذا أصبح السكان بعددون إلى شراء لتهاء

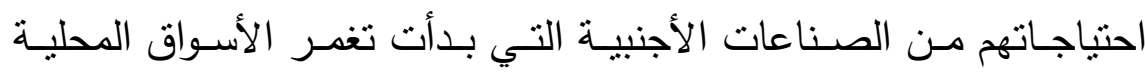


وتتتافس على جذب المستهلك. كما تراجعت الزراعة في بلدان الخليج بعد

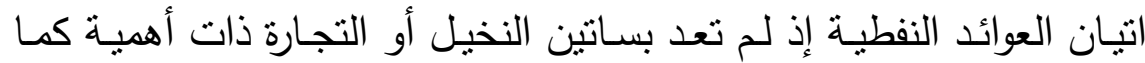
كانت في السـابق بعد انصراف السكان إلى استثمار أموالهم في المشاريع

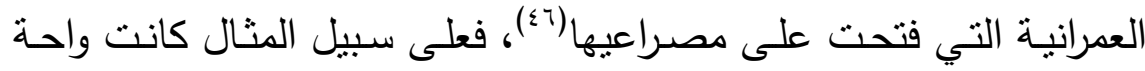

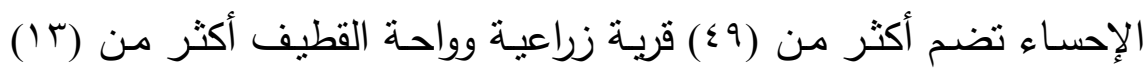

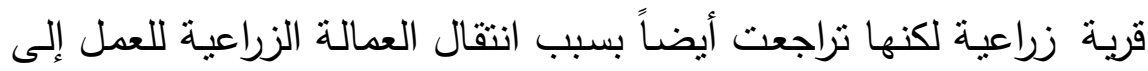

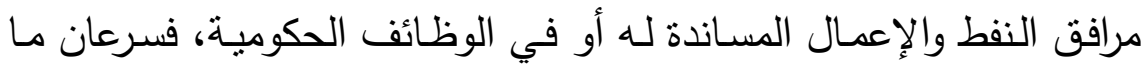

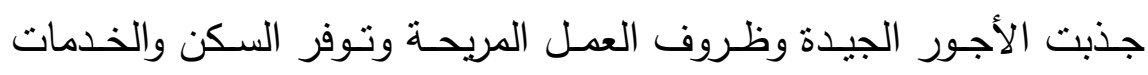

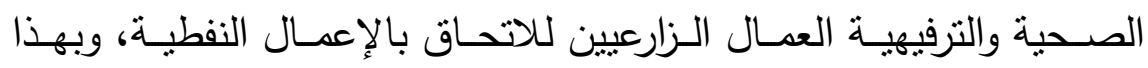

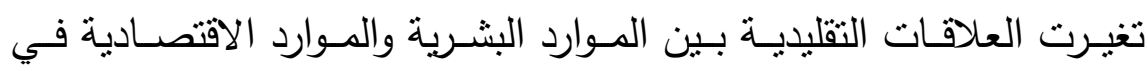
المجتمع بعد ظهور فرص عمل لم تكن معروفة من قبل، وإقبال الخليجيين

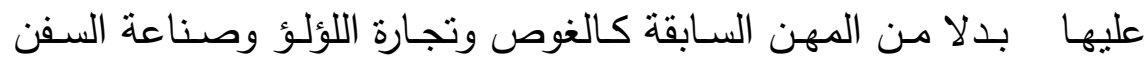

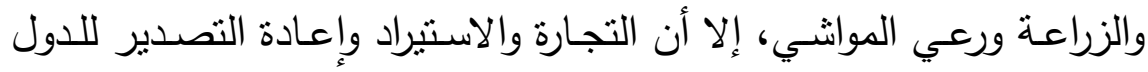

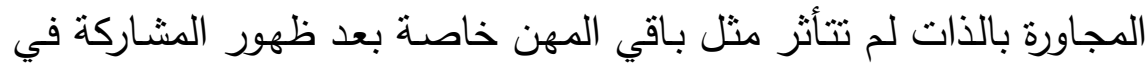

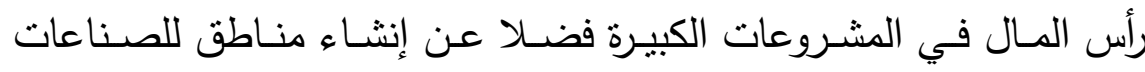

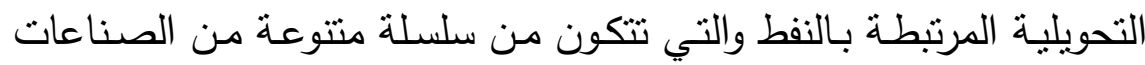

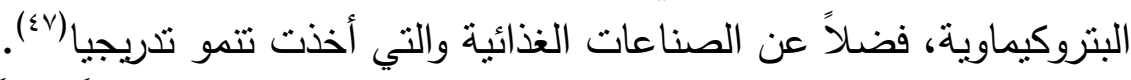

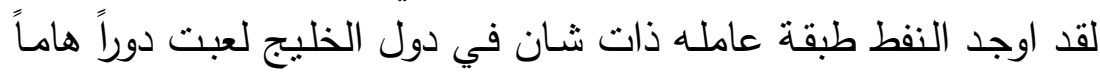

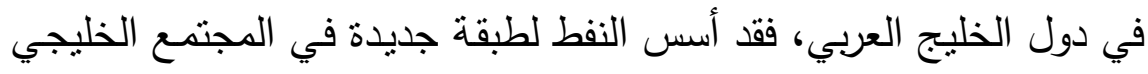
(الطبقة البرجوازية) إلا ان هذه الطبقة كان لها وجود في الكويت والبحرين

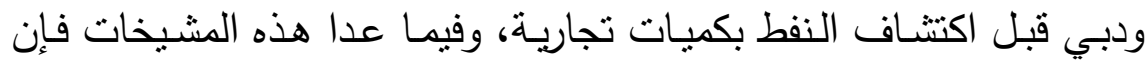
صناعة النفط هي التي أوجدت الطبقة البرجوازية في باقي مناطق الخليج العربي، كما ساعد النفط على قيام طبقات عاملة لها توجهات ايديولوجيـة لونية

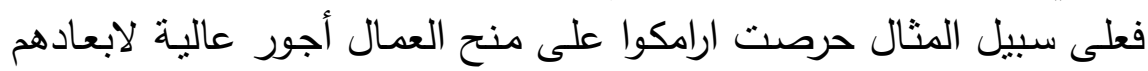

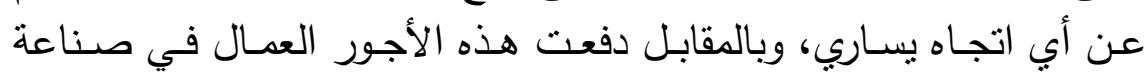


السفن وغيرها من المهن الى التوجه نحو الثركات النفطية لتحسين أحوالهم المعاشية فضلاً عن ذلك كانت الثركات تفضل العمالة المحلية على العربية

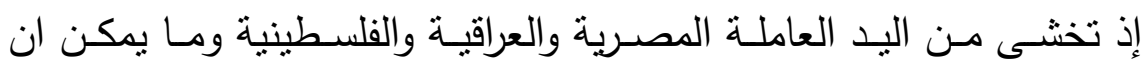

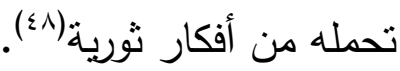
وبعد هذا الاستعراض البسيط للتحولات الاقتصادية التي أحدثها النفط في

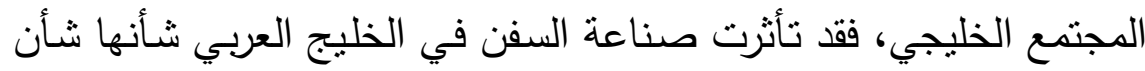

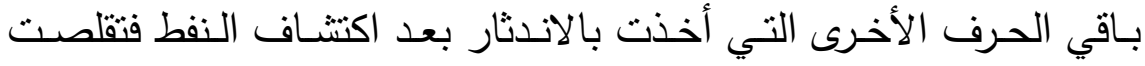
صناعة السفن بعد النفط وسيطرته على الحياة الاقتصادية في دول الخليج

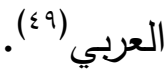
لقد ظلت صناعة السفن مزدهرة، على الأفل، حتى مطلع القرن العشربن

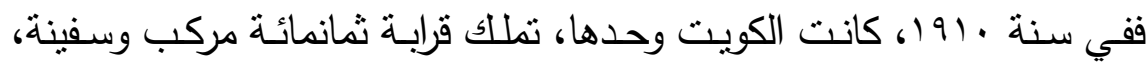

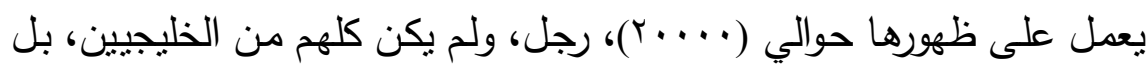

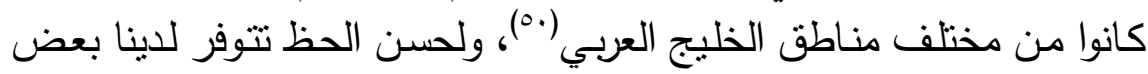
الاحصـاءات الأولية عن أنواع وأعداد السفن المملوكة لموانيء الخليج العربي

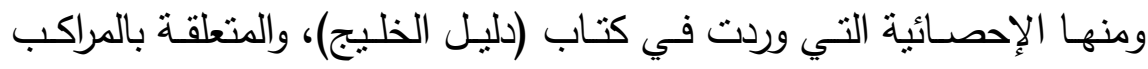

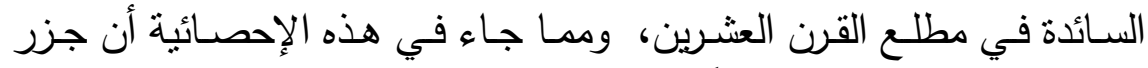

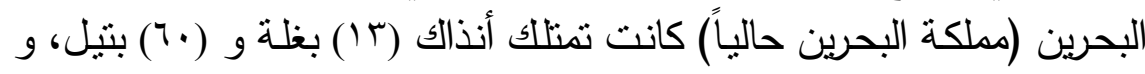

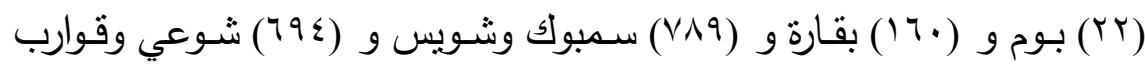

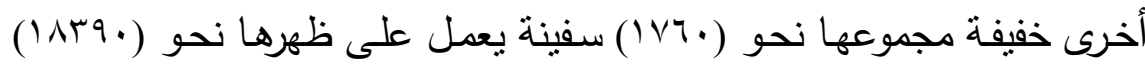

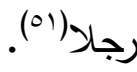

كذللك كان عدد السفن التي تعمل بالغوص نحو (10 (10) سفينة يعمل

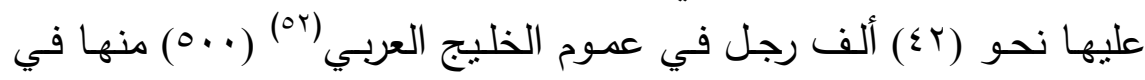

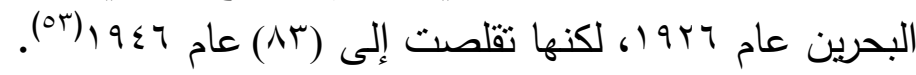

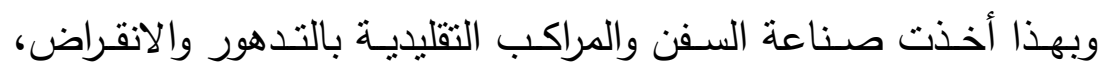

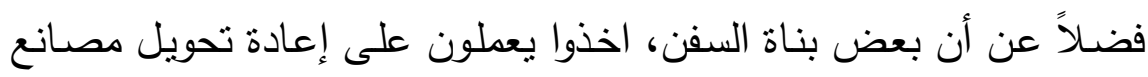

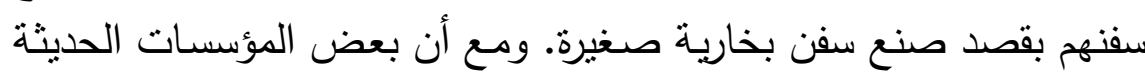


في بعض مناطق الخليج العربي تبذل جهوداً حثيتة من اجل الاحتفاظ

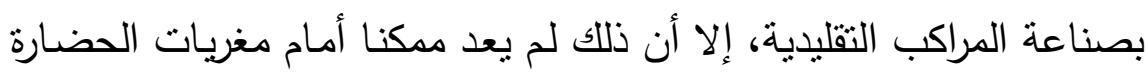

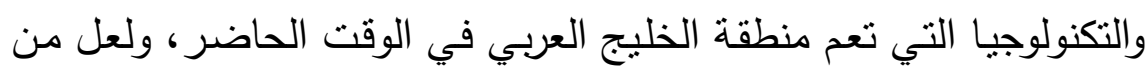

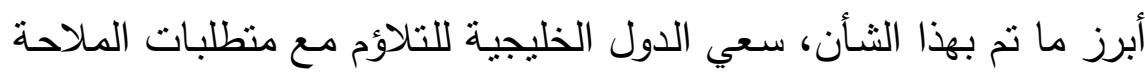

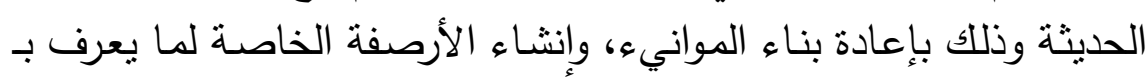

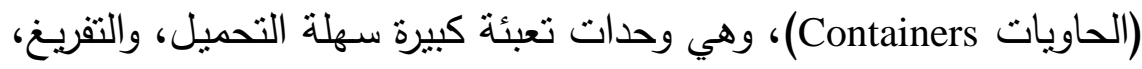

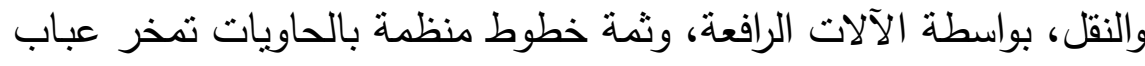

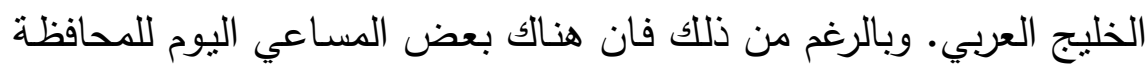

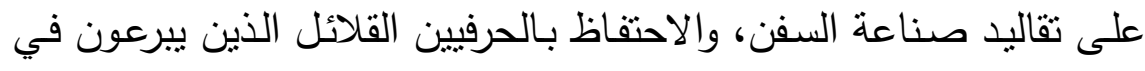

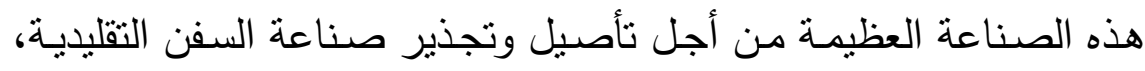

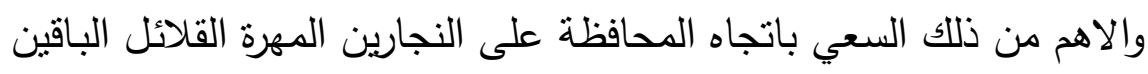

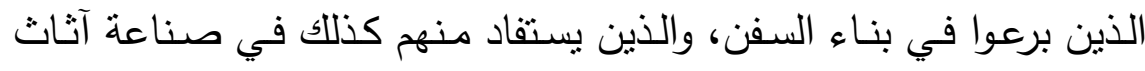

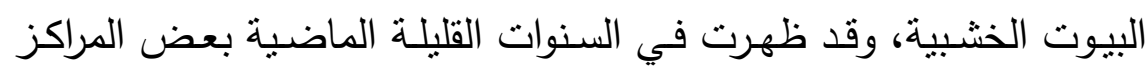

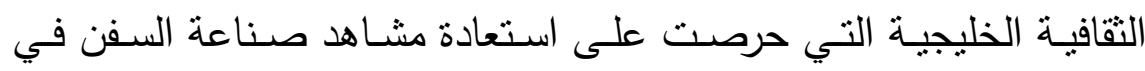

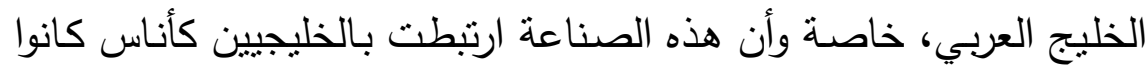

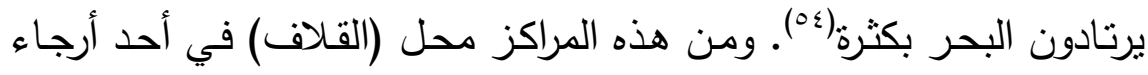

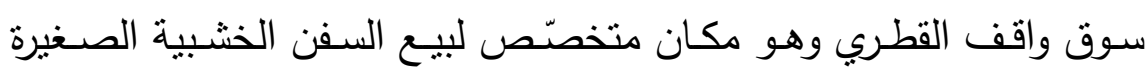

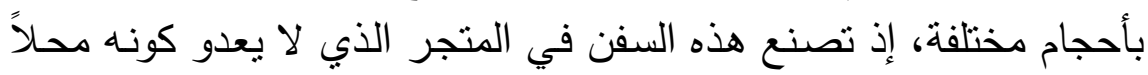

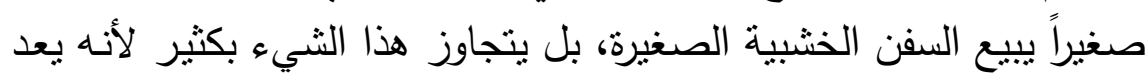

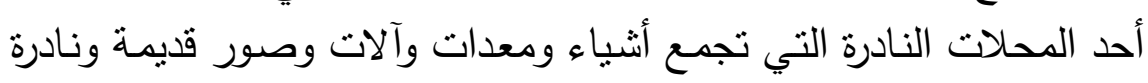

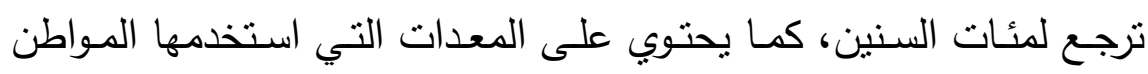

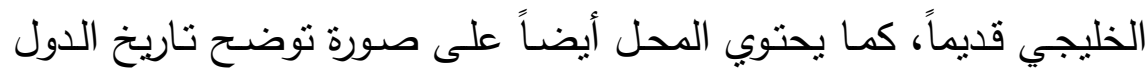
الخليجية حتى وقتتا الحاضر (00). 
برع أبناء الخليج العربي في المهن والحرف المتصلة بالبحر مثل صناعة

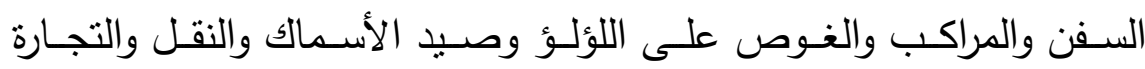

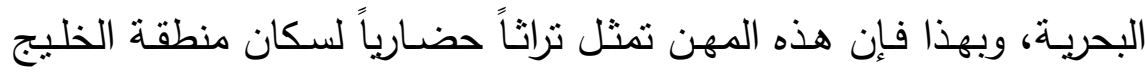

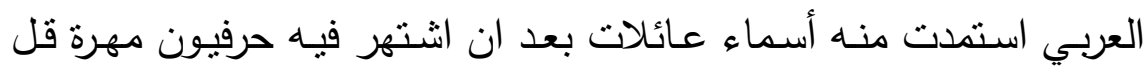
نظيرهم، فكانت نتاجاتهم تتم عن صنعة متقنة لسفن بقيت تستخدم لعشرات السنين وغواصون شجعان كسبوا قوتهم من حرفة صعبة لايستطيع إلا أهل

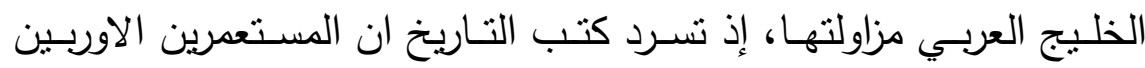

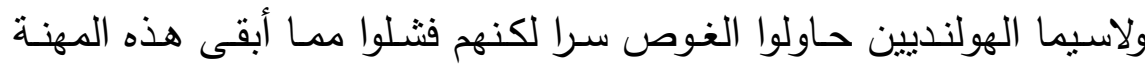
المهمة حكرا على عرب الخليج، وقد كانت صناعة السفن ابرز صناعات الخليج قبل اكتشاف النفط، ولم تكن للاستعمال في الخليج فقط بل كانت تصدر إلى مناطق أخرى لسمعتها التي كسبتها من جودة صنعتها، فكان لها الأثر الاقتصادي الكبير على دخل سكان المنطقة. ومن خلال البحث تم تمدي التوصل إلى عدد من الاستتتاجات أهمها:

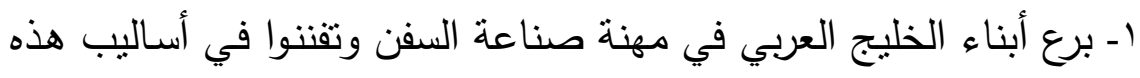
الصناعة، فكانت السفينة الخليجية مميزة عن غيرها من السفن.

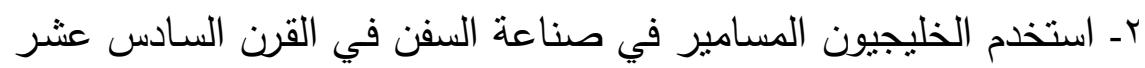
بعد احتكاكهم بالأوربيين.

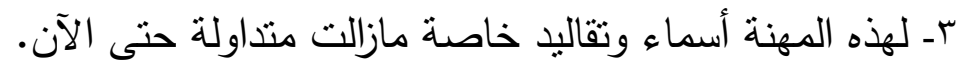

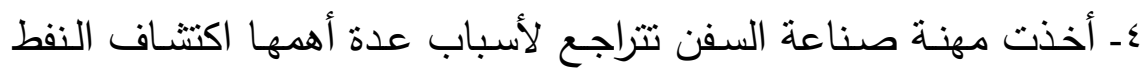
والتغيرات الجذرية التي أحدثها في المجتمعات الخليجية.

0- هناك دعوات للمحافظة على هذه الحرفة المميزة وتطوريها. ا- يوجد ارتباط وثثي بين حرفة صناعة السفن والغوص على اللؤلؤ فقد أدى الدى تطور المهنة الأولى في ازدهار الثانية والعكس صدئ صحيح. 


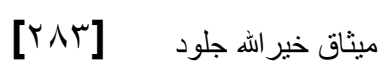
صناعة السفن في الخليج العربي...

الملاحق

ملحق رقم (1)

سنبوك مخيط بالحبال

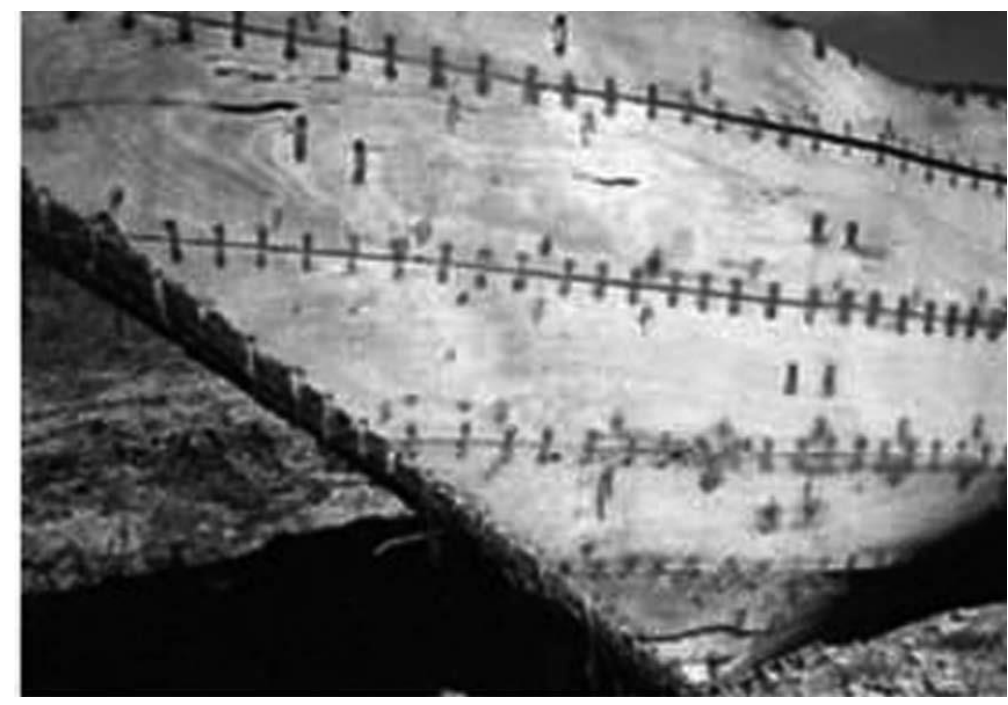

ملحق رقم (r)

السيوب ويأيدهم الحبال المتصلة بالغاصة

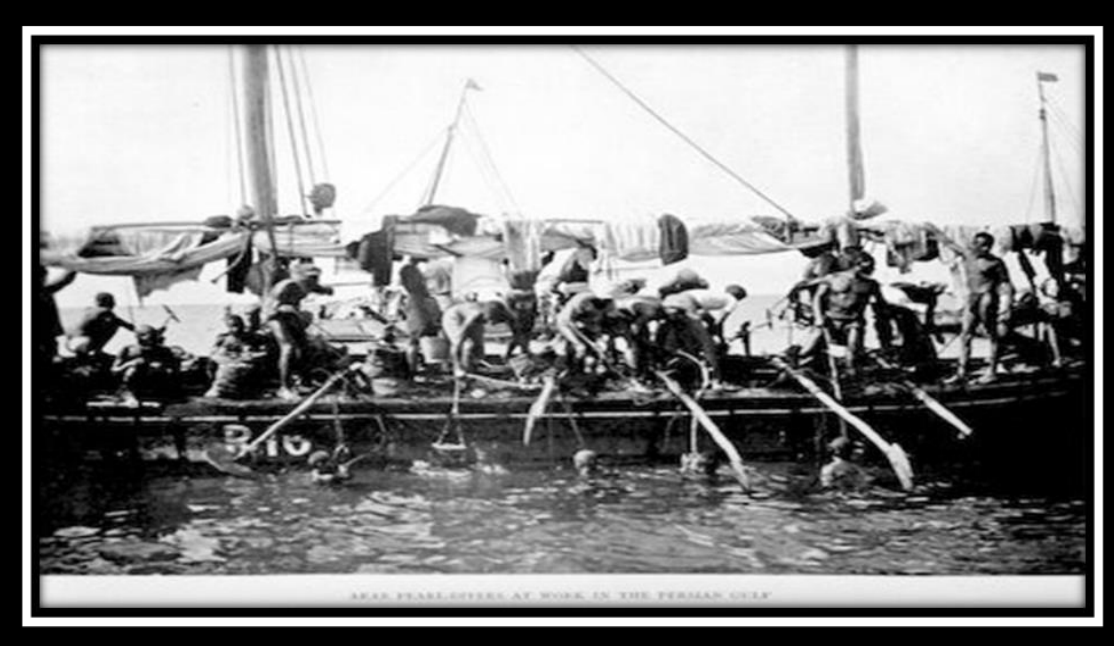




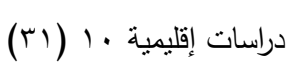

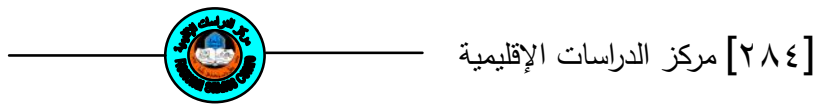

\title{
Ship Building In Arab Gulf And The Effect of Oil
} exploration In Its Collapse

\author{
Mr. Mithag K. Jalud \\ lectures, political strategic Dept. Regional Studies Center \\ Mansl University
}

\begin{abstract}
Ship building was the most economic a activities of Arab Gulf before exploring oil and the $\varepsilon^{\text {th }}$ and $\delta^{\text {th }}$ decades of $r \cdot{ }^{\text {th }}$ century Separated between two economic ages in the region. They are the age of diving looking for pearls and the oil age being considered the main resource for economy at present. This is true for ship building which began to collapse after changes taken place upon the Gulf society.

People in Arab Gulf were famous in crafts connected with Sea and these crafts represent a cultural heritage and families in the Gulf took its names. Their products express the art of ship building for years and it is necessary in keeping this sort of craft

الموامش والمصادر

(1) إبراهيم خليل العلاف، "السفن والمراكب في الخليج العربي..قصة كفاح مجيد"، الجمعية الدولية

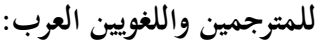

www.wata.cc/.../showthread.php

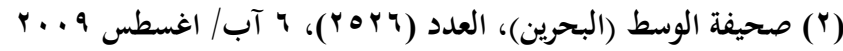




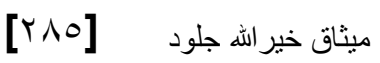
صناعة السفن في الخليج العربي... - صن

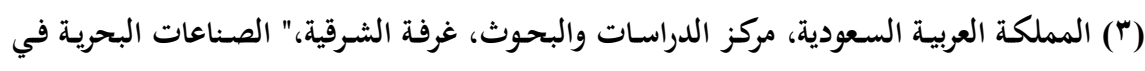

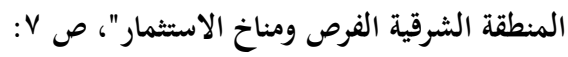

ww.chamber.org.sa

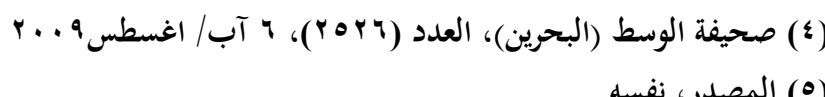

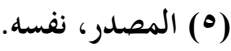

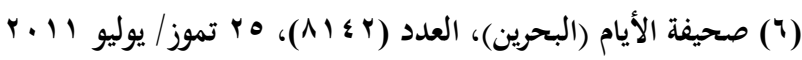

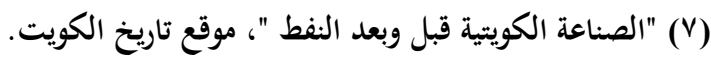

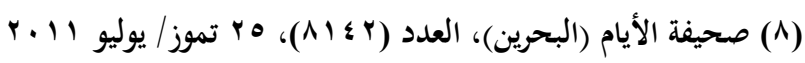

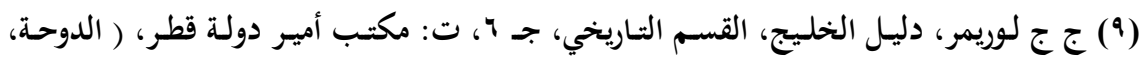

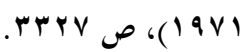

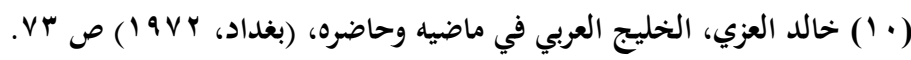

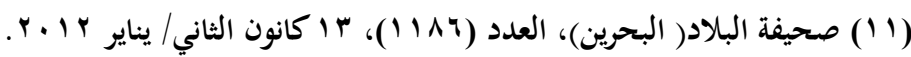

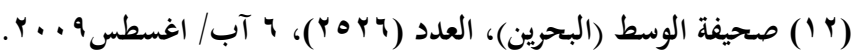

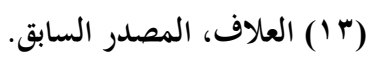

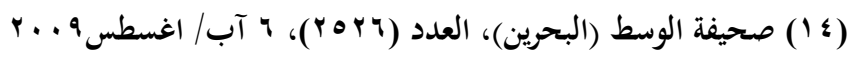
(10) (10) (1) العلاف، المصدر السابق.

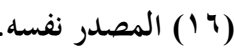

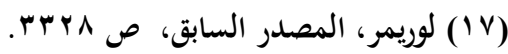

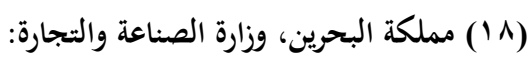

http://www.moic.gov/

$$
\begin{aligned}
& \text { (9 (19) العلاف، المصدر السابق. }
\end{aligned}
$$

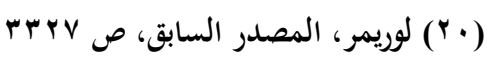

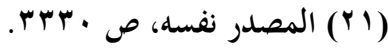

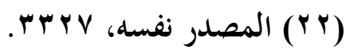

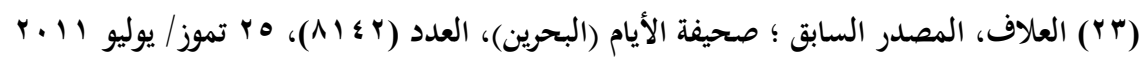

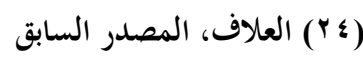

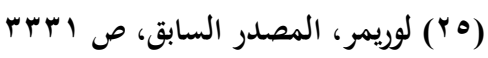




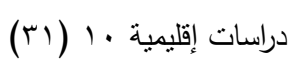

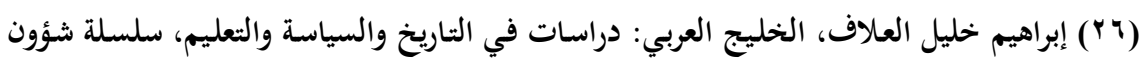

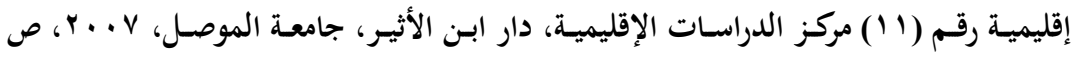

$$
\begin{aligned}
& \text { (YV) }
\end{aligned}
$$

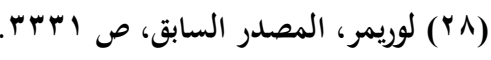

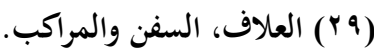

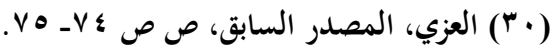

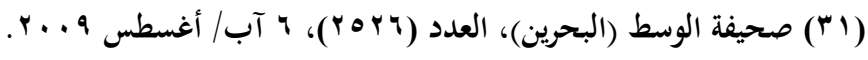

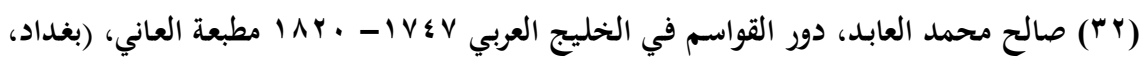

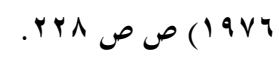

(rr (r) العلاف، السفن والمراكب.

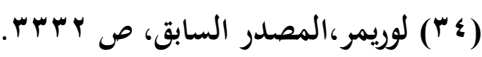

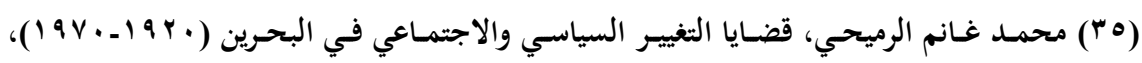

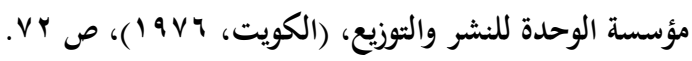

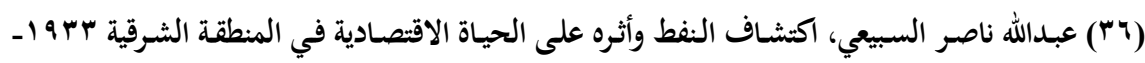

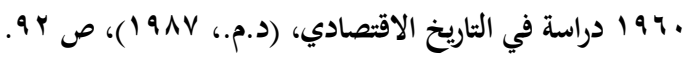

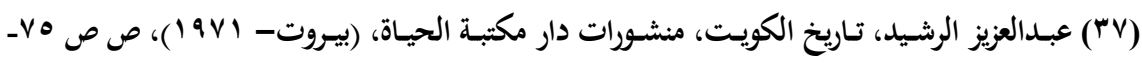

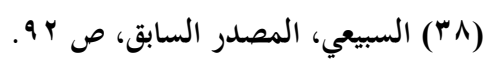

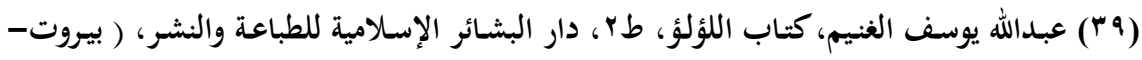

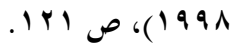

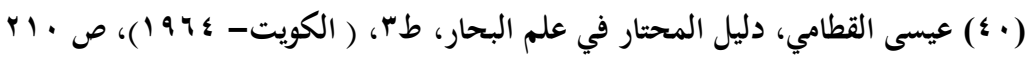

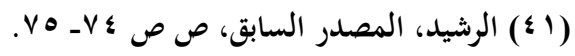

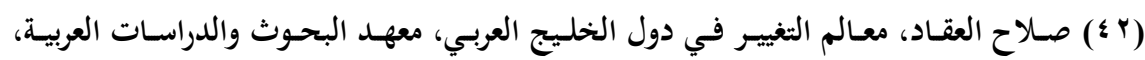

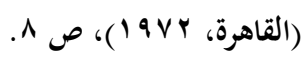

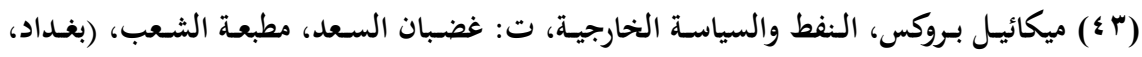

$$
\text { (1901 }
$$


[r^v] ميثاق خير اله جلود

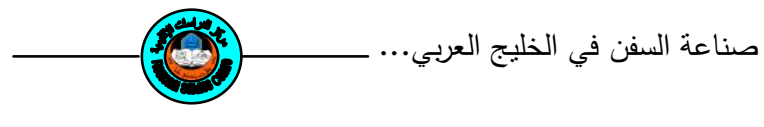

(؛ ؛ فتحي عباس الجبوري واحمد صالح الجبوري، تاريخ الخليج العربي، طا، دار الفكر، (عمان،

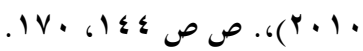

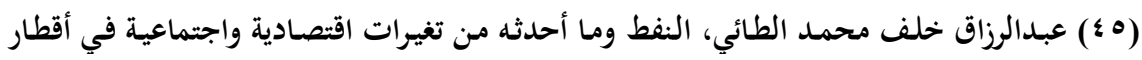

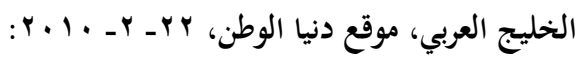

pulpit.alwatanvoice.com/content-19.1 1 r.html

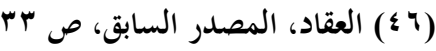
( ) الطيائي، المصدر السابق.

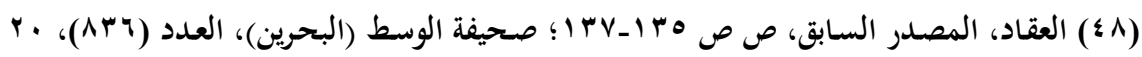

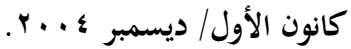

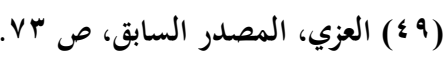

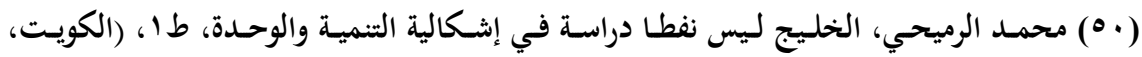

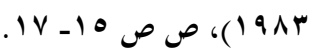

(10) العلاف، السفن والمراكب.

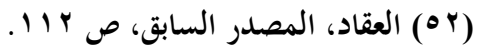

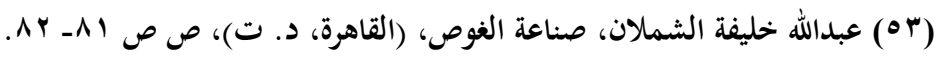

(؛ (ه) العلاف، السفن والمراكب.

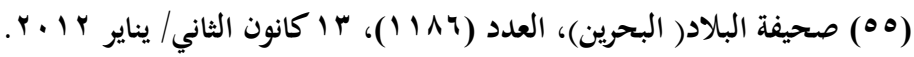

